\title{
LA APROPIACIÓN URBANA DE LOS MIGRANTES AYMARAS EN LA CIUDAD DE EL ALTO (BOLIVIA): UN ESTUDIO SOBRE LAS DINÁMICAS URBANAS Y LABORALES ${ }^{1}$
}

\section{URBAN APPROPRIATION OF AYMARA MIGRANTS IN THE CITY OF EL ALTO (BOLIVIA): A STUDY ABOUT URBAN AND LABOR DYNAMICS}

\author{
Mariela Paula Diaz²
}

\begin{abstract}
Resumen
La ciudad de El Alto (Bolivia) generalmente es descripta como un cinturón homogéneo de pobreza y de población de origen aymara. En cambio aquí se pretende debatir con esta imagen ya que se presenta evidencia empírica que demuestra la diferenciación socio espacial y el desarrollo urbano desigual (y combinado) de dicha ciudad según localización centro-periferia. De aquí la pertinencia de esta investigación cuyo objetivo es analizar la apropiación urbana de los migrantes aymaras residentes en dos barrios de la ciudad de El Alto, localizados en diferentes zonas de la misma y con distintos grados de consolidación urbana (el barrio de la zona periférica El Porvenir I y el del área céntrica 16 de Julio), en el periodo de la globalización postneoliberal 2010-2013. En el barrio periférico, a diferencia del barrio céntrico y antiguo, ocurre la configuración de territorios rururbanos, donde los migrantes empobrecidos mantienen un hilo de continuidad con sus comunidades. Para llevar a cabo esta investigación, se realizaron entrevistas semi-estructuradas en profundidad a la población migrante y se aplicó una encuesta a miembros de 100 hogares en total. También se destaca la observación no participante de las actividades de la vida cotidiana.
\end{abstract}

Palabras claves: Migración aymara-Territorios rururbanos- Informalidad laboral- Segregación residencial-Dinámica urbana.

\begin{abstract}
The city of El Alto (Bolivia) is generally described as a homogeneous belt of poverty and population of aymara origin. But here I want to discuss about this image with empirical evidence that shows the social and spatial differentiation and the unequal (and combined) urban development of the city. For this, the relevance of this research aimed at analyzing the urban appropriation of aymara migrants in two neighborhoods of the city of El Alto, located in different areas of the same and with different degrees of urban consolidation (the neighborhood of the uptown zone El Porvenir I and the downtown area 16 de Julio), in the period of post-neoliberal globalization 2010-2013. In the uptown, unlike the downtown and older quarter, setting rururban territories where migrants maintain a thread of continuity with their communities. To carry out this study, I conducted semistructured in- depth interviews to migrant residents and a survey was applied to members of 100 households in total. Also, I did non- participant observation of the activities of daily life.
\end{abstract}

Keywords: Aymara migrantion- Rururban territories-Labor informality- Residential segregationUrban dynamics

\footnotetext{
${ }^{1}$ Este artículo presenta resultados parciales de la tesis doctoral de la autora.

2 Doctora en Ciencias Sociales de la Universidad de Buenos Aires (UBA-Argentina). Docente en el Ciclo Básico Común en la asignatura "Sociología" y en la Maestría en Planificación Urbana y Regional de la Facultad de Arquitectura, Diseño y Urbanismo en la asignatura "Análisis estadístico", ambas materias de la UBA. Becaria postdoctoral del CONICET, con sede de trabajo en el Instituto Multidisciplinario de Historia y Ciencias Humanas (IMHICIHU, unidad ejecutora del CONICET). E-mail: madidip@gmail.com
} 


\section{INTRODUCCIÓN}

Actualmente, la ciudad de El Alto es la segunda urbe más poblada (843.934 habitantes) del país, luego de Santa Cruz (1.453.549 habitantes); contando con una extensión territorial de 350.4 km2, dividida políticamente en 14 distritos municipales ${ }^{3}$. Al mismo tiempo tuvo un rol importante en el mapa político de Bolivia y de Latinoamérica, ya que fue el centro de los levantamientos populares-aymaras de octubre de 2003 y de mayo/junio de 2005 (Mamani Ramírez, 2004) que dieron lugar al quiebre del ciclo neoliberal vigente en el país desde 1985 hasta la llegada de Evo Morales al poder en 2006.

Es definida como un enclave urbano homogéneo: el más pobre de la región metropolitana de La Paz y un espacio étnico (aymara) que posee una baja provisión de infraestructura básica en relación a La Paz (Gonzálvez, 1996; Adad Torrico, 2004; Guaygua, 2011 y Arbona, 2008)4. Por tal motivo, El Alto es considerado una ciudad aymara que es uno de los rasgos que permanece pese al proceso de urbanización y metropolización. Es descripta como una ciudad joven y de migrantes por su reciente conformación (septiembre de 1988) y por la composición de su población ${ }^{5}$.

Por lo tanto, se intentará demostrar que, lejos de la visión homogeneizante predominante en los informes académicos y gubernamentales bolivianos, la ciudad de El Alto presenta una diferenciación socio-espacial y un desarrollo urbano desigual y combinado según localización centro-periferia 6 .

El objetivo de este artículo es analizar las características de las prácticas cotidianas llevadas a cabo por la población migrante de origen rural y aymara en el barrio periférico El Porvenir I y en el barrio céntrico 16 de Julio (III sección) ${ }^{7}$ y las vinculaciones que existen con el tipo

\footnotetext{
${ }^{3}$ Cada uno de los distritos integra dentro de sí a un conjunto de barrios.

${ }^{4}$ En la década de los años 90 fue declarada ciudad en emergencia por este elevado crecimiento demográfico y las deficiencias en materia de servicios básicos.

${ }^{5}$ A nivel macro, esta descripción tiene asidero ya que, según el censo del año 2012, alrededor del 60\% de los habitantes tiene menos de 25 años y el $81,8 \%$ de los que tienen 15 años y más se autoidentifican con este pueblo aymara (Fuente:Censo, 2012). A su vez, desde el enfoque de NBI, según la información disponible hasta el momento, la población pobre en la ciudad de El Alto representaba al 66,9\% en el año 2001, porcentaje que superaba al que correspondía a la ciudad de La Paz $(34,5 \%)$, y al del país en su conjunto $(58,5 \%)$.

${ }^{6}$ Solamente se encuentran afirmaciones incipientes, con escasa evidencia empírica sistematizada, sobre la diferenciación socio-espacial que caracteriza a esta ciudad (Pereira Morató, 2009; Mazurek, 2009; Demoraes, 1998; Garfias y Mazurek, 2005; Durán Chuquimia et al., 2007).

7 Es importante aclarar que el barrio 16 de Julio se encuentra dividido en tres secciones. Se eligió la tercera ya que según la bibliografía consultada (Sandoval et al., 1989) era el lugar donde antiguamente se habían radicado los migrantes del campo
} 
de hábitat en el que residen y con su posición en el mercado laboral (es decir con la estructura de clase del hogar).

De este manera, se indaga sobre las dimensiones de la dinámica urbana: el hábitat o la configuración territorial, y el habitar o las estrategias de apropiación urbana; así como la interrelación entre ambas. Además, se aborda el lazo mantenido por los hogares de migrantes con sus comunidades de origen, es decir los movimientos pendulares campo-ciudad que permitirá examinar el supuesto proceso de descampenización.

Esta investigación pretende ser un aporte e insumo para futuras investigaciones sobre las ciudades andinas de nuestro continente. Como señaló Hubert Mazurek (2009), la sociología boliviana se ocupó muy poco de estudiar las transformaciones socio-territoriales en el marco del proceso de urbanización, y específicamente El Alto es una de las ciudades con menos estudios sobre su realidad (Durán Chuquinia et al, 2007). Al mismo tiempo, se han relevado investigaciones que analizan fragmentariamente la cuestión de la vivienda y el mercado de trabajo en la ciudad, siendo escasos los estudios que reconocen esta relación desde un anclaje socio-territorial y desde la perspectiva de la dinámica urbana.

Por otra parte, el periodo de estudio propuesto, entre los años 2010-2013 ${ }^{8}$, puede enmarcarse en el momento político latinoamericano denominado globalización posneoliberal ${ }^{9}$. Respecto a este último se halla actualmente un debate sobre si los gobiernos postneoliberales lograron menguar o no la dependencia. La discusión se balancea entre aquellos que conciben la existencia de una refundación del Estado en tanto ruptura con el neoliberalismo; y los que plantean un movimiento dialéctico y contradictorio entre continuidad y ruptura con el contexto anterior definido por el Consenso de Washington (Sader, 2008; Svampa, 2012; Lander, 2011).

En este escrito se sostiene que más allá de las diferencias en cuanto al rol del Estado entre el denominado neoliberalismo y postneoliberalismo, que de mero regulador pasó a desarrollar una

\footnotetext{
8 Es importante destacar que el neoliberalismo en Bolivia tuvo su punto de inflexión en agosto de 1985 cuando se aplicó el Decreto N²1060 bajo la presidencia de Víctor Paz Estenssoro del Movimiento Nacional Revolucionario (MNR). Esto ocurrió con posterioridad a la derrota de las jornadas de lucha de los trabajadores mineros (Diaz, 2013). Este periodo se extendió hasta la llegada a la presidencia de Evo Morales del Movimiento al Socialismo (MAS) en el año 2006, luego de un ciclo de rebeliones populares-aymaras (2000-2005), con epicentro en la ciudad de El Alto, que inauguró una etapa llamada postneoliberal que rige hasta el presente.

${ }^{9}$ La globalización (neoliberal y postneoliberal) es definida como una nueva fase de la mundialización del capitalismo que implicó transformaciones a nivel económico, político, cultural e ideológico. Como explicaron Harvey (2010) y Pradilla Cobos (2010), retomando a Marx, la mundialización del capitalismo se inició con la acumulación originaria de capital, y los "descubrimientos" y colonizaciones del siglo XVI. Desde entonces atravesó varias y diversas fases de este proceso.
} 
intervención directa en los distintos ámbitos de la sociedad con un componente parcialmente nacionalista y neodesarrollista, se mantienen las históricas asimetrías. En otras palabras, la dependencia estructural a los capitales trasnacionales y la permanencia de las desigualdades sociales que se reflejan en las altas tasas de informalidad laboral.

La perspectiva teórica adoptada retoma y problematiza especialmente los estudios sobre la urbanización latinoamericana de Jaramillo (1993 y 2012), que en general se han enfocado en una escala macro. Aquí se propone un análisis multiescalar (a nivel urbano y barrial) que demuestre los rasgos específicos de la urbanización latinoamericana y de las ciudades andinas con el fin de indagar sobre las posibles diferenciaciones según la localización centro y periferia. Por ende, la ciudad de El Alto se convierte en un caso testigo de las características propias de dichas urbes como marco general que permita, en un posterior trabajo, evaluar las especificidades y similitudes de los países de la región.

Para poder llevar a cabo esta investigación, que pretende abordar las dimensiones del hábitat y del habitar, se seleccionó una estrategia multimétodo que combina procedimientos cualitativos y cuantitativos, incorporando datos de fuentes primarias y secundarias. Especialmente se analizaron los informes publicados por el Instituto Nacional de Estadística de Bolivia.

Los datos cualitativos primarios provienen de las entrevistas semi-estructuradas en profundidad a mujeres y hombres migrantes residentes en cada uno de los barrios, y de la observación no participante de la vida cotidiana ${ }^{10}$. Para la realización de las entrevistas en los barrios bajo estudio se eligieron a hombres y mujeres de 18 años y más, y en total se entrevistaron a 40 personas (de manera individual o dentro del núcleo familiar) en base a los hogares integrados en la muestra estratégica (no probabilística) de una encuesta aplicada a 100 hogares en total (50 hogares en cada barrio). Esto fue combinado con la técnica bola de nieve a partir de las referencias aportadas por los sujetos a los que ya se había accedido. En todos los casos aparecen con sus nombres ficticios para resguardar su anonimato.

Los datos cuantitativos primarios son resultado de una encuesta a miembros de 50 hogares (en total 100 hogares que representan un total de 298 habitantes) en cada uno de los barrios que definen situaciones diferentes en la relación centro-periferia de la ciudad. Para la implementación de la misma se utilizó un muestreo estratégico (no probabilístico) donde el procedimiento de

\footnotetext{
${ }^{10}$ La observación no participante es lo que predominó. Excepto cuando la autora participó en noviembre de 2011, invitada por el presidente de la Junta Vecinal, en un festejo del barrio 16 de julio.
} 
selección muestral concluye cuando se llega a la saturación teórica. En este sentido, cada lugar en el que se aplicó la encuesta representa un tipo de hábitat característico de dicha ciudad.

La misma releva las características socio-demográficas y laborales de los miembros del hogar; las características de la vivienda y del vecindario respecto a la dotación de servicios públicos domiciliarios y de mantenimiento urbano, de infraestructura urbana y de equipamientos comunitarios; la relación que mantienen con sus comunidades de origen y las opiniones sobre los problemas principales del barrio. Esta información permitió identificar el contexto urbano (o el hábitat) de cada uno de los barrios en cuestión.

A continuación se detalla la perspectiva teórica del artículo. Luego un breve recorrido histórico sobre la conformación de El Alto como ciudad y se presentan los resultados principales, seguidos de unas conclusiones finales.

\section{EL ESTUDIO DE LA DINÁMICA URBANA: EL HÁBITAT Y EL HABITAR}

El estudio de la dinámica urbana implica una doble dimensión: la referente al hábitat y al habitar. Esta última indica los diversos modos de habitar, los usos, las representaciones y las estrategias de apropiación de la ciudad ${ }^{11}$ que se efectivizan mediante las prácticas cotidianas que permiten satisfacer necesidades sociales (Vershambre, 2005; Stébé y Hervé, 2011; Lefebvre, 1978; Harvey, 2007).

Por consiguiente, habitar implica apropiarse del espacio, que no es sinónimo de propiedad, sino de hacer su obra, de modelarla, de ponerle el sello propio. En este sentido, no es meramente un acto de reproducción, y a su vez, el término apropiación excede la cuestión jurídica.

La configuración territorial o el hábitat hacen referencia a las oportunidades diferenciales que ofrece la ciudad ligada a la distribución espacial desigual de los servicios públicos domiciliarios, de infraestructura, de equipamientos comunitarios, entre otros, condición de posibilidad de la existencia de rentas diferenciales en el suelo urbano. En otras palabras, la concentración de los mismos tiende a aumentar el precio del suelo y configura los lugares céntricos o consolidados de la ciudad. En consecuencia, ciertas zonas (periféricas) que no otorgan al capital las condiciones generales de valorización permanecen inexplotadas, generando diversas situaciones de penurias

\footnotetext{
${ }^{11}$ Las estrategias de apropiación urbana forman parte de las estrategias familiares de reproducción en un contexto estructural que las condicionan (Duhau, 2003; Dureau, 2003, Di Virgilio, 2007).
} 
(Topalov, 1979). Por lo tanto, las condiciones del hábitat incluyen las características de la vivienda y del contexto urbano (vecindario) ${ }^{12}$.

Asimismo, esta diferenciación en el territorio de las condiciones de valorización explica en parte la noción de desarrollo urbano desigual y combinado. Por este motivo, no se parte de una visión finalista (y dualista) del proceso de urbanización: la concentración de las actividades sociales y de la población en las ciudades, y la desaparición de las áreas rurales (Pradilla Cobos, 1986).

En aumento, las ciudades expresan un desarrollo urbano desigual y combinado que manifiesta la incesante acumulación y concentración del capital en espacios reducidos y conlleva la combinación entre lo más desarrollado de la técnica con lo más tradicional; determinado por el proceso anárquico de la acumulación del capital (Harvey, 2004; Smith, 2006). De este modo las zonas periféricas y céntricas, en contraste con la teoría de la modernización ${ }^{13}$, no forman parte de una ciudad dual sino que son las dos caras de un mismo proceso histórico (Stavenhagen, 1965; Quijano, 1973; González Casanova, 1970; Pradilla Cobos, 2010).

Además, este concepto se vincula con ciertos rasgos específicos de la urbanización latinoamericana: la deficiente provisión de los valores de uso colectivo, la agudeza de la segregación residencial en un contexto de urbanización popular e informal; la informalidad laboral ligada a la presencia de formas -no mercantiles/pre capitalistas- de producción y de socialización del consumo; y la denominada isla de ruralidad (Jaramillo et al, 1983). Sobre esta última, se opta por conceptualizarla como territorio rururbano asociado a las prácticas cotidianas híbridas que dan lugar a un tipo de hábitat donde ocurre una mixtura de usos del suelo.

En esta perspectiva de análisis, los rasgos particulares que aluden al hábitat popular de las urbanizaciones latinoamericanas son indicadores no sólo de la configuración territorial sino también de la dimensión del habitar, es decir de las estrategias de apropiación del territorio. Por consiguiente, estas dos dimensiones no deben estudiarse de manera dicotómica sino en su relación dialéctica. Es así que las características del hábitat condicionan las posibilidades de apropiación y las formas de habitar de una población pero, a su vez, éstas pueden dar como resultado un tipo de hábitat particular.

12 Desde una utilidad metodológica se separa la vivienda del entorno urbano, ya que se adhiere a una concepción amplia de vivienda como hábitat o medio ambiente, que se define como una configuración de servicios urbanos (servicios habitacionales) los cuales satisfacen un abanico amplio de necesidades, que se especifican en el devenir histórico, soporte y condición de la reproducción de las relaciones sociales en y de la ciudad (Yujnovsky, 1984; Lombardo, 2012).

${ }^{13} \mathrm{El}$ exponente en Argentina fue el sociólogo Gino Germani. Este autor explicaba que el desarrollo industrial en las periferias y la subsiguiente migración campo-ciudad contenían el pasaje de un tipo de sociedad arcaico, tradicional y rural a otro urbano, moderno e industrial (Camarero, 2000). 


\section{BREVE RELATO HISTÓRICO: DE BARRIO A CIUDAD}

Para fines del siglo XIX y principios del siglo XX, gran parte del territorio de El Alto estaba concentrado en manos de latifundistas. En el altiplano norte, a diferencia de otras regiones de Bolivia, las haciendas se erigieron sobre los territorios de las comunidades indígenas aymaras ${ }^{14}($ ayllu) donde se presentaba la combinación de una tenencia (posesión) privada o familiar de espacios de tierra cultivable y la propiedad comunal (Ballivián, 2009). Con posterioridad sobre la base de dichas haciendas se conformaron los barrios alteños.

Hacia mediados del siglo XX, El Alto se consolidó como un barrio periférico de la ciudad de La Paz y se constituyó principalmente como dormitorio obrero. Su conformación fue parte del proceso de metropolización y consolidación urbana de La Paz que comenzó específicamente a partir de las transformaciones sociales, políticas y económicas de la Revolución de 1952. Entre ellas, se destacan la Reforma Agraria de 1953, la eliminación del pongueaje ${ }^{15}$ y la Reforma Urbana de 1954.

Estas transformaciones permitieron el asentamiento de la población indígena en las ciudades. Hasta ese momento, tenía prohibido la entrada a ciertas calles céntricas y plazas de La Paz. En consecuencia, el crecimiento poblacional de La Paz permitió el emplazamiento de cinturones periféricos. De este modo, incorporó a El Alto como su apéndice, constituyendo un lugar alternativo de residencia de la población migrante ya que fundamentalmente, en este período, se dirigían a las laderas de la ciudad.

Para ese entonces, La Paz era uno de los focos más importantes de atracción principalmente porque se encontraba la fuente laboral de esta población, y El Alto por la altitud (4050 metros sobre el nivel del mar), el clima (propio de la puna) y la carencia de los componentes colectivos básicos del hábitat se estructuraba como un foco secundario o alternativo de recepción de migrantes.

Un suceso importante fue la implementación de la Reforma Agraria (1953). Bajo la presión popular y la presencia de milicias obreras y campesinas se llevó a cabo la expropiación de las

\footnotetext{
${ }^{14}$ Cabe aclarar que en la actualidad la autoidentificación con el pueblo aymara sigue predominando en la urbe alteña.

${ }^{15}$ La hacienda puede ser considerada, como un sistema de concentración de la propiedad privada, que mantuvo la tradición de opresión económica y social de la masa indígena, lo que puede asemejarse a una mezcla entre esclavitud (pongueaje en el caso de los hombres, mitanaje en el de las mujeres) y segregación racial. Aunque fue formalmente proscripta en 1945 por el gobierno de Villarroel, en la práctica estuvo vigente otros siete años (Dunkerley, 2003).
} 
haciendas ${ }^{16} \mathrm{y}$ bajo el lema la tierra es de quien la trabaja se entregaron pequeñas parcelas a los campesinos ${ }^{17}$. Paradójicamente, esta reforma facilitó la fragmentación territorial que generó un libre mercado de terrenos. Siguiendo a Arbona et al (2011), que los campesinos de una hacienda accedieran a comprar el terreno indicaba una anomalía, ya que lo que ocurrió fue más bien una (re) apropiación. Es así que una minoría de campesinos acomodados compró a bajo precio las parcelas de sus ex comunarios para luego lotear de manera informal.

Cabe destacar que Bolivia, hasta principios de la década de 1950, se caracterizaba por un predominio rural e indio campesino $(73,8 \%$ de la población total) cuyo peso, aunque menor, continúa actualmente $(32,7 \%)$.

Cuadro 1: Población total según área de residencia. Bolivia. Censos de 1950, 1976, 1992, 2001 y 2012. En porcentajes.

\begin{tabular}{|c|c|c|c|c|c|}
\hline Área & 1950 & 1976 & 1992 & 2001 & 2012 \\
\hline Urbana & 26.2 & 41.7 & 57.54 & 62.4 & 67,3 \\
\hline Rural & 73.8 & 58.3 & 42.45 & 37.6 & 32,7 \\
\hline Total (Bolivia) & $100(2704165)$ & 100 & 100 & 100 & 100 \\
\hline & & (4613419) & (6420792) & (8274325) & (10027254) \\
\hline
\end{tabular}

Fuente: Elaboración propia según los Censos Nacionales de Población y Vivienda de 1950, 1976, 1992, 2001 y 2012

Esto muestra que el proceso de urbanización de los países andinos, particularmente Bolivia, Ecuador y Perú, muestran importantes diferencias con respecto a otras áreas del continente. Esto se debe a diversos motivos, entre ellos: el peso del pasado colonial y de las áreas rurales, la importancia de las culturas indígenas, las particulares relaciones entre ciudad y campo, la mayor debilidad del desarrollo industrial durante el siglo XX y el impulso de una urbanización tardía (Adad, 2004; Cuadros, 2003).

A su vez, en este contexto se comprende la conformación, por parte de los latifundistas alteños (cuyas iniciativas de loteamientos en la década de 1940 se aceleraron post Revolución) y de los campesinos acomodados, de un submercado de loteamientos informales, convirtiéndose en los

\footnotetext{
${ }^{16}$ Entre los años 1953 y 1975 se distribuyeron más de 19 millones de hectáreas, es decir sólo 17,3\% del territorio nacional. Pero, en la provincia Murillo, donde se encuentran la ciudad de La Paz y El Alto, se distribuyó casi la mitad del territorio total, que comprende unas 228 mil hectáreas (Arbona et al,2011). En estas expropiaciones se indemnizaron a los latifundistas.

${ }^{17}$ Esta reforma se concretó en El Alto con la expropiación de la hacienda El Tejar, que ocupaba toda la zona de la Ceja, el actual centro cívico y comercial.
} 
llamados urbanizadores piratas (Jaramillo, 2012; Abramo, 2012). De este modo, surgieron un conjunto de barrios informales dispersos, sin dotación de servicios y criterios urbanísticos ni puntos de articulación urbana. Los servicios tales como agua, energía eléctrica, alcantarillado, etc., se estimaban que serían provistos después de una primera fase de parcelación especulativa y la simultánea segunda fase de edificación. Este proceso de loteamiento barato e informal permitió el asentamiento de los sectores de migrantes empobrecidos quienes autoconstruyeron como una estrategia de acceso a la vivienda propia.

A partir de la década de 1980, El Alto recibió el desborde poblacional de las laderas de la hoyada de La Paz, y se convirtió en el primer polo de atracción de las nuevas migraciones que se produjeron en el país producto de la aplicación de las medidas neoliberales. Este crecimiento de El Alto se debió, en parte, a los limitantes de relieve que presenta el valle donde se ubica la ciudad de La Paz. Esta última al estar situada en un valle cerrado y accidentado tiene restringidas posibilidades de expansión, que le impide construir en cualquier zona. Al contrario, El Alto presenta un relieve plano sin accidentes geográficos relevantes. Solamente posee dos límites: uno físico (la cordillera), y otro político-administrativo (los Municipios vecinos).

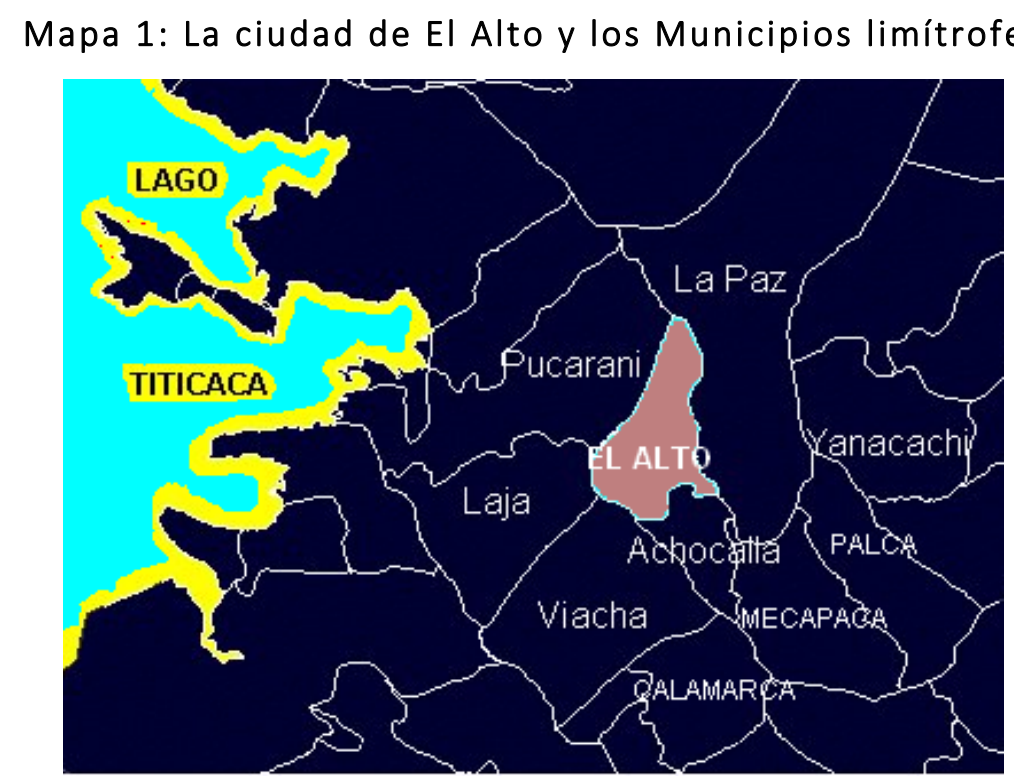

Fuente: Gobierno Autónomo Municipal de El Alto, 2008

En marzo de 1985 se transformó en municipio autónomo: dejó de llamarse El Alto de La Paz por simplemente El Alto y la población pudo elegir a sus propias autoridades municipales. Finalmente, en septiembre de 1988 fue reconocido por el Congreso Nacional su estatus de ciudad. También, El Alto dejó de ser un lugar meramente de residencia. Durante los años 80, pero con 
mayor énfasis en la década de 1990, se convirtió en una ciudad mercado y en una ciudad manufacturera e industria ${ }^{18}$.

Pese a no contar con estadísticas oficiales que estimen la incidencia de la informalidad laboral, se deduce que la misma debe ser alta debido a que las principales actividades económicas de la ciudad son, en primer lugar, el comercio y los servicios, y le sigue la industria manufacturera. En consecuencia, la producción en pequeña escala de bienes y servicios de primera necesidad destinados al mercado interno son los principales generadores de empleo e ingresos (Wanderley, 2009).

El crecimiento más fuerte de esta ciudad (y el más alto de Sudamérica) se registró en el período intercensal 1976-1992 (la tasa anual de crecimiento intercensal alcanzó el 9,2\%) ${ }^{19}$, por varios factores económicos y sociales.

\section{Cuadro 2: Tasa anual de crecimiento intercensal (TACI) 1976-1992, 1992-2001 y} 2001 y 2012. Ciudad de El Alto. Censo 1976, 1992, 2001 y 2012. En porcentajes.

\begin{tabular}{|c|c|c|c|}
\hline Área & TACl 1976-1992 & TACl 1992-2001 & TACl 2001-2012 \\
\hline Ciudad de La Paz & 1,8 & 1,1 & $-0,3$ \\
\hline Ciudad de El Alto & 9,2 & 5,1 & 2,3 \\
\hline Bolivia & 2,1 & 2,7 & 1,7 \\
\hline
\end{tabular}

Fuente: Censos Nacionales de Población y Vivienda de 1976, 1992 y 2001.

Principalmente, las transformaciones neoliberales plasmadas en el Decreto Nㅜㄴ 21060 bajo el gobierno de Paz Estenssoro de agosto de 1985, provocaron las oleadas migratorias de las consideradas víctimas del sistema (los mineros, los fabriles y los campesinos), lo que dio impulso al proceso de urbanización del país.

En este periodo se sucedió la relocalización minera por el cierre de las empresas mineras del Estado en el marco de la política de reducción de gasto estatal y de desplome del precio del estaño. De este modo, la COMIBOL despidió a más de 30.000 obreros mineros. Lo mismo ocurrió en el sector fabril, que por la liberalización de la economía, no pudo competir con los productos importados, los cuales se vieron favorecidos en materia arancelaria.

Simultáneamente, los pobladores rurales del Altiplano Norte, producto de las sequías en tierras bajas e inundaciones en zonas montañosas por efecto del Niño de los años 1982-83, de la

\footnotetext{
${ }^{18}$ El 90,6\% del total de las unidades económicas manufactureras son microempresas (Primer Censo de Establecimientos Económicos de la Industria Manufacturera en la ciudad de El Alto, 2003).

${ }^{19}$ Esta tasa fue ampliamente superior a las tasas de crecimiento de las principales ciudades del eje central del país. Para el mismo período (1976-1992), la tasa de crecimiento anual de La Paz fue de 1,8\%, de Cochabamba $4,2 \%$ y de Santa Cruz 6,4 \% (Garfías y Mazurek, 2005).
} 
crisis agraria debido a la apertura económica, y del problema estructural del minifundio, se dirigieron a la ciudad de El Alto (donde el precio de los terrenos eran -y siguen siendo-más baratos que en La Paz), y a otras ciudades del eje central (Do Alto, 2007). En las ciudades, los migrantes empobrecidos lograron insertarse en una economía informal y precarizada (Klein, 2002).

Por este motivo, se afirma la existencia de un proceso de descampenización en los países andinos que se ven reflejados en los datos estadísticos. No obstante, como quedará demostrado más adelante, esta población de origen rural desarrolla apropiaciones urbanas específicas y mantiene estrechas relaciones con sus comunidades de origen que configuran un tipo de hábitat particular en la ciudad que contradice la perspectiva clásica de la teoría de la modernización.

Este vertiginoso crecimiento poblacional de El Alto, que puso de manifiesto la tasa de crecimiento intercensal 1976-1992, sucedió de una manera informal y sin ningún tipo de planificación estatal alrededor de los tres ejes de expansión: hacia la carretera a Copacabana, a Viacha y a Oruro. Esto a pesar de las pocas urbanizaciones creadas por los planes estatales de vivienda durante el periodo 1950-1980, focalizados especialmente en los asalariados formales. Esto último se enmarca en el contexto propio de los países andinos donde se destacan recursos públicos aún más limitados, definiéndose claramente una combinación de "islas de riqueza" en "un mar de pobreza" (Adad, 2004).

\section{Mapa 2: Las principales carreteras de la ciudad de El Alto}

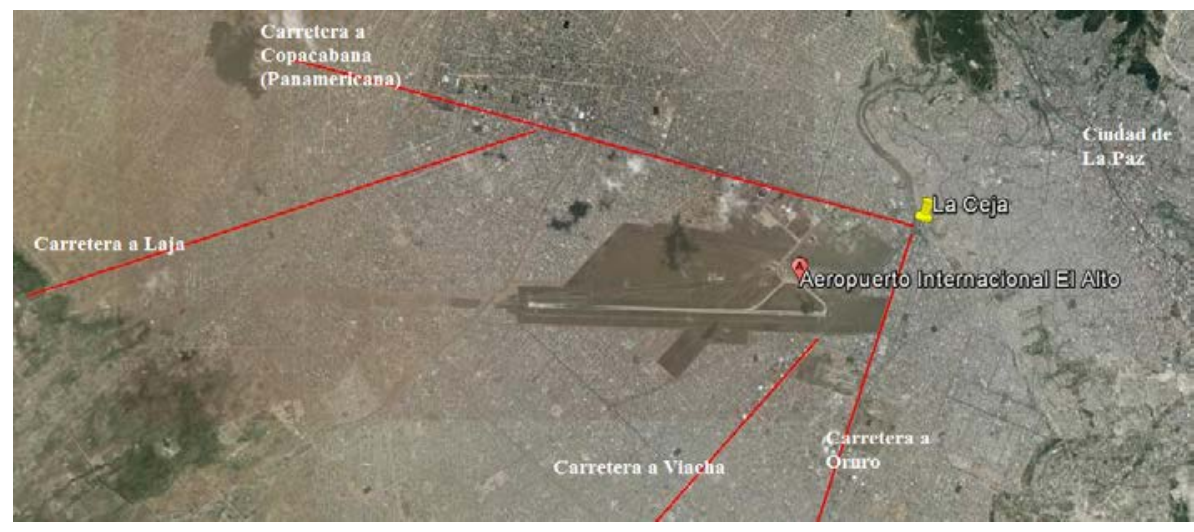

Fuente: Elaboración propia

Recuperando los estudios de Abramo (2012) sobre la producción de una estructura urbana COM-FUSA en Brasil a partir de la interacción entre el mercado formal e informal del suelo, se puede indicar que estas migraciones internas produjeron también en El Alto una tendencia a la extensión continua que promovió una estructura territorial difusa en la periferia (de baja consolidación urbana) y compacta en las zonas céntricas de consolidación "relativa". Esta extensión 
de las periferias (sin infraestructura ni servicios básicos) expresa las estrategias de los loteadores informales de minimizar los costos de fraccionamiento y maximizar las ganancias (Abramo, 2012; Pirez, 2014) $)^{20}$.

\section{CARACTERÍSTICAS SOCIO-DEMOGRÁFICAS Y LABORALES DE LA POBLACIÓN BAJO ESTUDIO}

El barrio 16 de Julio es un barrio céntrico que se encuentra al norte de la ciudad (en el Distrito 6) y se conformó el 16 de julio de 1944. Es considerado uno de los barrios más antiguos ya que fue uno de los primeros que se originaron luego de la guerra del Chaco (1932-1935). Al presente es una de las áreas con mayor consolidación urbana, aunque relativa ya que posee deficiencias estructurales por resolver, característica propia de las urbanizaciones periféricas que cuentan con una baja provisión de valores de uso colectivo (Jaramillo et al., 1993). Aquí prevalece una mezcla de usos de suelo urbano: residencial, comercial e industrial (manufacturero).

Por el contrario, el barrio El Porvenir I, se fundó el 2 de febrero de 1999 y se halla en el sector noroeste de la periferia de la ciudad de El Alto (en el Distrito 7). Este Distrito es considerado el segundo más extenso de El Alto y el que menos población posee, constituyéndose así en un área periférica en proceso de expansión (Alvarado et al, 2011) ${ }^{21}$.

Por consiguiente, la conformación de estos barrios sucedió en dos momentos económicos, políticos y sociales distintos. En la década de 1950, la urbanización del país se aceleró bajo el período de Capitalismo de Estado cuando se desarrolló la política de industrialización por sustitución de importaciones y se aplicaron diversas reformas políticas y sociales. En cambio, hacia mediados de los años 80 , bajo los gobiernos democráticos neoliberales, el crecimiento poblacional en las áreas urbanas y la migración campo-ciudad, fue una consecuencia de la política de desindustrialización (relativa), de la apertura económica y de la liberalización de la economía 22 .

\footnotetext{
${ }^{20}$ A mediados de los años 80 , el impacto de la dolarización en el precio de la tierra urbana y en el conjunto del mercado inmobiliario "empujó" a los sectores populares hacia los suelos más baratos de la periferia (Durán Chuquinia et al, 2007)

${ }^{21}$ El Porvenir I es considerado un "barrio de engorde", ya que muchos mantienen sus predios desahitados para luego vender o alojarse cuando se establezcan todos los servicios básicos; mientras tanto residen en las zonas más céntricas de la ciudad.

${ }^{22}$ Pese a la distancia temporal, ya que El Porvenir se constituyó hacia fines de los años 90 y el barrio 16 de Julio hacia mediados de los años 40, fue el loteamiento informal sin provisión de servicios básicos ni infraestructura urbana, lo que permitió el acceso de los sectores populares y migrantes de las comunidades rurales.
} 


\section{Mapa 3: La localización de los barrios alteños El Porvenir I y 16 de Julio}

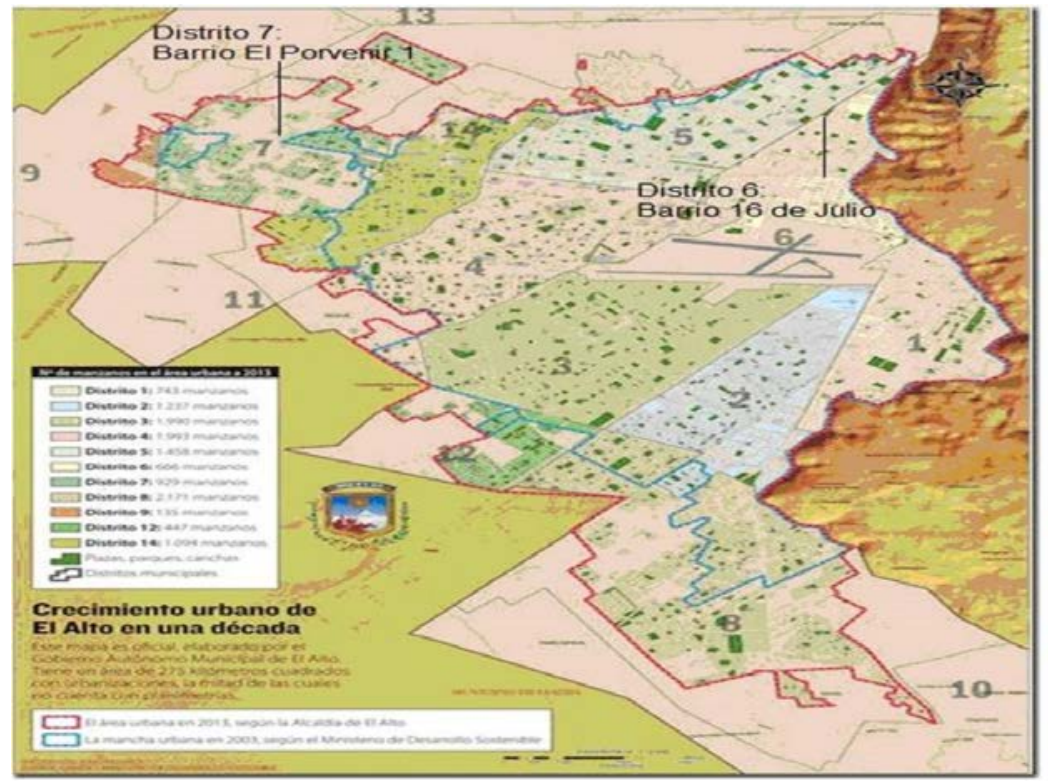

Fuente: Gobierno Autónomo Municipal de El Alto (2013)

En cuanto a la composición social, en el barrio periférico predominan los hogares con adultos nacidos en el campo (94\%), que se autoidentifican con el pueblo indígena aymara. En cambio, en el barrio 16 de Julio imperan los hogares con adultos nacidos en la ciudad de El Alto o La Paz (60\%), donde el $53,5 \%$ se autoidentifica con ese pueblo y un $20 \%$ con ningún pueblo indígena o nación ${ }^{23}$. Es probable que en esta zona muchos de ellos sean hijos o nietos de migrantes, esta temática podría abordarse en una futura investigación.

En el grupo poblacional de 65 años y más, el 50\% de la misma provenía de las comunidades rurales y el otro $50 \%$ de las ciudades de La Paz o El Alto, lo que denota que en sus orígenes recibió un contingente de población rural. Esto se enmarca en el proceso de expansión urbana de El Alto que dio lugar a la constitución del barrio 16 de Julio como el primer destino de la población migrante. Mientras, El Porvenir I aglutina la población aymara migrante del campo, luego de haber atravesado varias etapas migratorias previas desde su salida de la comunidad de origen.

Igualmente, El Porvenir I posee una estructura poblacional más joven que el barrio céntrico (el 55\% del total de los miembros del hogar tiene menos de 20 años; en 16 de Julio alcanza al 37,6\%). Por ende, estos datos enfrentan la imagen homogénea de la ciudad El Alto ya que se presenta una distribución espacial desigual de la cultura aymara y de la población migrante, así como de la estructura poblacional joven en la ciudad según su localización centro-periferia.

${ }^{23}$ La nueva Constitución Política del Estado Plurinacional de Bolivia (2009) reconoce la existencia de 36 naciones, es decir, ya no son denominados como etnias los distintos pueblos indígenas. 
Respecto al perfil socioeconómico, los jefes de hogar de ambos barrios se concentran como trabajadores por cuenta propia sin empleados a su cargo y como obreros/empleados.

\section{Cuadro 3: Ocupación principal de los jefes de hogar activos. Total de hogares de los barrios El Porvenir I y 16 de Julio. Año 2012. En porcentajes. ${ }^{24}$}

\begin{tabular}{|c|c|c|c|c|c|c|}
\hline \multirow{2}{*}{ Barrio } & \multicolumn{5}{|c|}{ ¿Cuál es la ocupación principal del jefe de hogar? } \\
\cline { 2 - 7 } & $\begin{array}{c}\text { Obrero/ } \\
\text { Empleado }\end{array}$ & $\begin{array}{c}\text { Trabajador por } \\
\text { cuenta propia con } \\
\text { empleados a su } \\
\text { cargo (Patrones } \\
\text { pequeños) }\end{array}$ & $\begin{array}{c}\text { Trabajador por } \\
\text { cuenta propia } \\
\text { sin empleados a } \\
\text { su cargo }\end{array}$ & $\begin{array}{c}\text { Empleada } \\
\text { doméstica }\end{array}$ & Ns/Nc & Total \\
\hline El Porvenir I & 42 & 6 & 48 & 0 & 4 & $100(50)$ \\
\hline 16 de Julio & 28,9 & 11,1 & 37,8 & 6,7 & 15,5 & $100(45)$ \\
\hline
\end{tabular}

Fuente: Elaboración propia según la encuesta realizada en el año 2012

Puede observarse que los barrios bajo estudio revelan la composición socio-económica de El Alto, que según el Censo 2012, está compuesta principalmente por obreros/empleados (43\%) y trabajadores por cuenta propia sin empleados a su cargo (43,3\%). Las actividades cuentapropistas se ligan principalmente con los microemprendimientos (emplean entre uno y cuatro trabajadores) que preponderan en la ciudad de El Alto. Estas son consideradas formas productivas precapitalistas de producción ya que se sustenta en el trabajo no asalariado. Suelen desarrollarse en el seno familiar y en un lugar físico particular de la vivienda de residencia. En este sentido, son llamadas viviendas productivas.

Ahora bien, como señaló Marx en El Capital respecto al trabajo domiciliario a destajo, esta actividad económica informal puede estar subordinada a los requerimientos de empresas tanto locales como extranjeras, y darse una "subsunción formal del trabajo al capital". Es decir, el proceso de trabajo se convierte en el instrumento del proceso de valorización del capital, donde

\footnotetext{
${ }^{24}$ Bajo la categoría "No sabe, no contesta" se agrupa a aquellos casos donde se relevó la ocupación y no la categoría ocupacional solicitada.
} 
éste se ubica como dirigente o conductor ${ }^{25}$, pero esta subsunción al capital es formal en cuanto se apoya sobre un proceso laboral preexistente (precapitralista). ${ }^{26}$

La utilización de la vivienda no solamente como un lugar de alojamiento sino de trabajo es una estrategia familiar de inserción en el mercado laboral. Esta práctica de autoempleo se masificó a partir de los años 80 como una forma de paliar el desempleo producto de la crisis económica que vivió el país en esa década y las consecuencias sociales que trajo consigo la aplicación de las medidas neoliberales.

La proliferación de las microindustrias enuncia no sólo los límites del mercado laboral para absorber a la totalidad de la población sino también puede manifestar la estrategia del capital de reducir sus costos de producción. Además, esto se vincula con un problema estructural de Bolivia, como país dependiente, que se basa en un patrón de crecimiento económico centrado en el sector primario exportador, que no genera puestos de trabajo suficientes para el conjunto de la población (Wanderley, 2009).

De aquí se desprende el problema estructural de la informalidad laboral en la ciudad de El Alto, y en Bolivia en general. En este país, hacia el año 2010, aproximadamente el $90 \%$ de la población económicamente activa (asalariados y cuentrapropistas no calificados) era informal desde la perspectiva legal (Tornarolli et al., 2009 y 2012; Portes et al., 2004). Pese a que la informalidad laboral es un rasgo de las urbes de América Latina; y que desde la década del 2000 (bajo los gobiernos denominados postneoliberales) ocurrió un fuerte crecimiento económico y de creación de empleo, la reducción en la incidencia de la informalidad laboral fue moderada. Sin embargo, es notoria la heterogeneidad de situaciones que presentan los países que componen la región ${ }^{27}$.

Como explicó Portes (2004), la informalidad no es sinónimo de ilegalidad. Esto se debe a que las actividades informales están relacionadas con bienes lícitos. Entonces, la diferencia fundamental entre la economía formal y la informal no guardan relación con las características del producto final sino con la forma en que éste es producido o intercambiado.

\footnotetext{
${ }^{25}$ De este modo, entrega materia prima y puede adelantar capital para las herramientas y manutención de los trabajadores pero no controla directamente el proceso de trabajo o no es el apropiador directo del proceso de producción y tampoco el comprador directo del trabajo.

${ }^{26}$ Sobre la base de un modo de trabajo preexistente, sólo se puede producir plusvalía recurriendo a la prolongación del tiempo de trabajo, es decir bajo la forma de plusvalía absoluta.

${ }^{27}$ Por ejemplo, hacia el año 2010, en Uruguay, Chile y Argentina este indicador se aproximaba al 40\% (Tornarolli et al., 2012).
} 
A nivel conceptual, existen dos definiciones de informalidad laboral, la legal (o de protección social) y la productiva. La primera refiere a los trabajadores en actividades económicas que no se encuentran registrados o regulados por el Estado, es decir exentos de protección laboral y seguridad social. En otras palabras, las empresas informales no cumplen con las normas en materia de contratos de trabajo y sus trabajadores no tienen derecho a la protección laboral o a los beneficios sociales vinculados al empleo.

La segunda describe a los trabajadores que se encuentran en empleos de baja productividad con tecnología rudimentaria, en una escala pequeña- marginal y, a menudo, en actividades basadas en la mano de obra familiar. Bajo esta última concepción, se incluyen a los trabajadores por cuenta propia sin empleados a su cargo no calificados ${ }^{28}$, a los trabajadores o aprendices familiares sin remuneración y a los asalariados en una pequeña empresa o microempresa (Portes 2004; Gasparini y Tornarolli, 2009).

Frente a estas dos acepciones, aquí se privilegia la definición legal y para su medición se utiliza como indicador empírico la realización de los aportes jubilatorios por parte de los empleadores, o la realización de los mismos en el caso de los trabajadores por cuenta propia sin empleados a su cargo (Tornarolli et al., 2009 y 2012). Este tipo de informalidad asociado al trabajo no registrado constituye una de las formas más aguda de precarización laboral (Neffa, 2010) ${ }^{29}$.

Desde esta perspectiva de análisis, la informalidad laboral de los jefes de hogar es lo que prevalece en ambos barrios (el 93,8\% del total de jefes de hogar de El Porvenir I, y en 16 de Julio el 97,7\%). Pese a que bajo el gobierno de Evo Morales se derogó el artículo del Decreto Supremo N²1060 que aludía a la liberalización del mercado laboral, esto no trajo consigo una liquidación del empleo informal y precario.

\footnotetext{
${ }^{28}$ Los "no calificados" son aquellos trabajadores sin un título terciario o superior.

${ }^{29}$ Es necesario recordar que aunque pueda darse en forma conjunta, los elementos constitutivos de la informalidad y la precariedad no son idénticos ya que el trabajo precario puede estar presente en actividades económicas informales y formales, y la informalidad en empresas privadas o en las mismas instituciones estatales (Neffa, 2010).
} 


\section{Cuadro 4: Tipo de inserción en el mercado laboral de los jefes de hogar (activos). Total de hogares de los barrios El Porvenir I y 16 de Julio. Año 2012. En porcentajes.

\begin{tabular}{|c|c|c|c|}
\hline \multirow{2}{*}{ Nombre del Barrio } & \multicolumn{3}{|c|}{ Tipo de inserción en el mercado laboral } \\
\cline { 2 - 4 } & Informal & Formal & Total \\
\hline El Porvenir I & 93,8 & 6,2 & $100(48)$ \\
\hline 16 de Julio & 97,7 & 2,3 & $100(44)$ \\
\hline Fuente: Elaboración propia según encuesta realizada en el año 2012
\end{tabular}

Sin embargo, puede analizarse la inestabilidad del empleo como un indicador adicional de precariedad y de empobrecimiento de los obreros/empleados y cuentapropistas sin empleados a su cargo. Esto último se enlaza con los menores ingresos y la menor disponibilidad de capital en el caso de los cuentapropistas, asociado a la inestabilidad. De esta manera, se distinguen actividades informales consolidadas o no consolidadas (Rojas y Guaygua, 2001; Rojas y Rossel, 2006; Guaygua y Escobar, 2008). Como se puede observar en el Cuadro 5, en El Porvenir I rige la inestabilidad laboral o el empleo temporario (54,2\%), mientras en 16 de Julio la estabilidad (57,5\%).

Cuadro 5: Calidad de la ocupación de los jefes de hogar (activos). Total de hogares de El Porvenir I y 16 de Julio. Año 2012. En porcentajes.

\begin{tabular}{|c|c|c|c|}
\hline \multirow{2}{*}{ Nombre del Barrio } & \multicolumn{2}{|c|}{ Calidad de la Ocupación } & \multirow{2}{*}{ Total } \\
\cline { 2 - 3 } & Permanente & Temporario & \\
\hline El Porvenir I & 45,8 & 54,2 & $100(48)$ \\
\hline 16 de Julio & 57,5 & 42,5 & $100(40)$ \\
\hline
\end{tabular}

Fuente: Elaboración propia según encuesta realizada en el año 2012

En conclusión, se demuestra una diferenciación socio-espacial en dicha ciudad en relación a su composición socio-demográfica, dinámica migratoria y laboral según la localización centroperiferia definida.

\section{LA DIMENSIÓN DEL HÁBITAT: FORMALIDAD DOMINIAL Y PRECARIEDAD URBANA}

Lejos de una visión lineal o economicista, como señaló Herzer el al (2008), los sectores populares pueden participar simultáneamente en actividades formales o informales del mercado de trabajo y el de tierra/vivienda. La informalidad urbana, según los estudios de Clichevsky (2000 y 
2003), comprende dos formas de transgresiones: respecto a los aspectos dominiales que se basa en la falta de títulos de propiedad (o contratos de alquiler); y en relación al proceso de urbanización en cuanto al incumplimiento de las normas de construcción de la ciudad. Esta última se compone de las tierras sin condiciones urbano-ambientales para ser usadas como residenciales, es decir: sin infraestructura y/o equipamientos colectivos, con dificultad en el acceso al transporte público, a los centros de empleo, a la educación primaria y a los servicios de salud.

Se aborda la informalidad urbana desde la primera "transgresión" (dominial) descripta. En cambio, la segunda transgresión es estudiada en referencia a la precariedad de la vivienda y de los componentes colectivos del hábitat que puede caracterizar tanto a la construcción del espacio urbano formal como informal. El estudio de la informalidad urbana y de la precariedad del hábitat puede convertirse (aunque no necesariamente) en un indicador de segregación residencial de la población que habita en un territorio determinado. Por lo tanto, las condiciones del hábitat popular pueden definirse entonces por diversas vinculaciones entre la informalidad y la precariedad.

En contraste con el barrio céntrico 16 de Julio, El Porvenir I posee una baja consolidación urbana y es descripta como un área segregada (que configura un tipo de hábitat). Este concepto se define no sólo como la tendencia de la organización del espacio en zonas de fuerte homogeneidad social interna y de fuerte disparidad entre ellas, sino esencialmente las oportunidades diferenciales de acceso a los bienes materiales y simbólicos de la ciudad.

Desde la mirada de autores clásicos y latinoamericanos (Massey y Denton, 1998; Castells, 1994; Sabatini et al, 2001; Améndola, 2000; Groisman y Suárez, 2006 y 2010; Rodríguez, 2008; Fernández Wagner et al., 2009; Adaszko, 2013), la segregación social conlleva entonces un contexto de homegeneidad espacial/urbana y social.

La homogeneidad social es medida a partir de la condición migratoria, la autoidentificación étnica de los adultos del hogar y su relación con la posición (del considerado jefe de hogar) en el mercado de trabajo. De este modo se propone estudiar la estructura de clase y étnica de una manera conjunta y no dicotómica ${ }^{30}$. Esto no es usual en los estudios actuales sobre la temática en América Latina, los cuales se han focalizado especialmente en la dimensión económica del proceso de segregación residencial.

\footnotetext{
30 Respecto a esta cuestión, Quijano (2000) sostuvo que hay un elemento de colonialidad en el capitalismo mundial actual que surge de la dependencia colonial, el cual clasifica a la población según la idea de raza e impone una división racial del trabajo.
} 
Por su parte, la siguiente tipología de vivienda precaria (que agrupa a aquellos hogares que cumplieron al menos una de estas condiciones) presenta los indicadores urbanos principales para el estudio de la segregación residencial en particular (en tanto homogeneidad espacial) y del contexto urbano en general: sin red de gas domiciliario, sin red de agua potable, sin baño, con piso de tierra, con baño (pero sin arrastre de agua), con red de agua potable domiciliario pero con distribución por cañería sólo en el patio o en el baño de la casa.

\section{Cuadro 6: Tipología de vivienda. Total de hogares de los barrios El Porvenir I y 16 de Julio. Año 2012. En porcentajes.}

\begin{tabular}{|c|c|c|}
\hline \multirow{2}{*}{ Tipo de vivienda } & \multicolumn{2}{|c|}{ Nombre del Barrio } \\
\cline { 2 - 3 } & El Porvenir I & 16 de Julio \\
\hline Vivienda precaria & 100 & 58 \\
\hline Vivienda no precaria & 0 & 42 \\
\hline Total & $100(50)$ & $100(50)$ \\
\hline
\end{tabular}

Fuente: Elaboración propia según encuesta realizada en el 2012

En El Porvenir I, la totalidad de las viviendas de los hogares encuestados es precaria, ya que se parte de una situación estructural homogénea que se caracteriza por la ausencia de gas natural a domicilio, la distribución de agua por cañería se encuentra sólo en el patio de la casa, y las viviendas que tienen baño no tienen arrastre de agua. De esta manera, el hábitat de este barrio se caracteriza por el predominio de una situación homogénea en cuanto a la precariedad de la vivienda y del entorno urbano. Este último posee una baja consolidación y cuenta con reducidas inversiones en obras públicas, infraestructura urbana, equipamientos comunitarios y problemas agudos en la accesibilidad ${ }^{31}$.

En otras palabras, en el barrio periférico se concentran los hogares de migrantes de origen aymara que constituyen la fracción más empobrecida de los trabajadores y sectores populares. Así, la situación de segregación residencial de la población del barrio periférico está asociada a la condición migratoria e indígena de los adultos del hogar y a un tipo de inserción laboral del considerado jefe de hogar.

\footnotetext{
${ }^{31}$ El transporte público sólo pasa por la carretera Panamericana (con dirección a Copacabana) y no ingresa a las vías principales del barrio. A partir de las 20 hs. comienza a escasear. Por ende, la movilidad urbana de las áreas periféricas de la ciudad es limitada.
} 
En el barrio 16 de Julio se encontró una cierta heterogeneidad ya que coexiste en un mismo espacio lo precario (que es lo que predomina sin distinción migratoria con el 58\%) y lo no precario en un contexto urbano de mayor consolidación. Por consiguiente, la segregación residencial que sufren los hogares de migrantes y la heterogeneidad incluso dentro del mismo barrio céntrico son una muestra del desarrollo urbano desigual y combinado que presenta la ciudad de El Alto.

La situación urbana y laboral de ambos barrios atenta contra el Derecho a la Ciudad. Esta última noción, según Fernández Wagner et al (2009), en sintonía con lo planteado por Jordi Borja (2011), implica el derecho a vivir en un hábitat integrado a los servicios, a la infraestructura urbana y a las oportunidades educativas y laborales.

Es significativo que en ambos barrios predomina la formalidad dominial, representando en El Porvenir I el 76\% y en 16 de Julio el 70,8\% de los hogares encuestados. Esta inserción formal actual, en contraste con los orígenes de la conformación de ambas zonas, se debe a una política concreta del gobierno local de regularización de la situación dominial de la población de la ciudad, base sobre la cual la Alcaldía ejerce su "derecho" de cobro del impuesto al inmueble 32 .

Este contexto en cuanto a la cobertura de los servicios públicos domiciliarios se considera un avance post levantamiento aymara de octubre de 2003 y de mayo/junio de 2005, no obstante se deduce que las mismas se siguen concentrando en las áreas céntricas de mayor densidad poblacional y edilicia, dejando al margen a las áreas periféricas de la ciudad.

En resumen, como analizaron Ramírez Corzo y Riofrío (2006) para el caso de los barriaras populares de Lima (Perú), se destacan los límites de la regularización dominial ante la inexistencia de una política urbana integral por parte del Estado. Es así que continúa una lógica "viviendista" (Coulomb, 2012) que no ataca el problema principal que es el déficit cualitativo de la vivienda.

\footnotetext{
32 Esta situación donde confluye la formalidad dominial y la precariedad urbana debate con la postura liberal acerca de la mejora del hábitat cuando la población se transforma en propietaria. Por ejemplo, Hernando de Soto (2004) sostenía que la erradicación de la pobreza en los llamados países del tercer mundo y en los que salían del comunismo debía basarse en la formalización de los sistemas de propiedad debido a la generación de "seis efectos esenciales para que sus ciudadanos puedan producir capital".
} 


\section{LA DIMENSIÓN DEL HABITAR: LAS PRÁCTICAS COTIDIANAS Y LOS MOVIMIENTOS PENDULARES}

\section{Territorios rururbanos en la periferia de la ciudad}

En esta sección se considera la relación de los hogares de migrantes con las prácticas cotidianas en ambos barrios. Este análisis se centra en la dimensión del habitar; en las estrategias de apropiación del espacio público y privado.

La existencia de "prácticas cotidianas híbridas" en el barrio El Porvenir I (que implican actividades rurales dentro de un entorno urbano) alude a una forma particular de apropiación urbana que pone de manifiesto las estrategias de acceso de los hogares de migrantes a un hábitat segregado y de baja consolidación urbana.

Estas prácticas configuran un territorio rururbano que dan como resultado un tipo de hábitat donde ocurre una mixtura de usos del suelo urbano ${ }^{33} y$ rural. En lugar de ser analizadas como islas de ruralidad (Jaramillo et al., 1993), se subraya su mixtura.

Entonces, cabe preguntarse si es posible una coexistencia de elementos heterogéneos sin fusión (Rivera Cusicanqui, 2010), o por el contrario una mixtura superadora de usos del suelo urbanos y rurales. De este modo, se presenta evidencia empírica que contradice la idea de que el proceso de urbanización es una tendencia evolutiva, absoluta y sin contradicción.

Situaciones típicas del barrio periférico fueron observadas en las actividades de doña Yolanda (42 años). Mientras se encontraba en un predio baldío confeccionando sus adobes, indicador de autoconstrucción de la vivienda, sus animales (porcinos y aves de corral) estaban en la vereda o en la calle del barrio. En los terrenos de las viviendas, todos con patio adelante, fue común ver sembradíos de papas, habas y otras verduras, característica peculiar que no se pudo corroborar en el barrio 16 de Julio. En El Porvenir I, estas actividades de índole rural forman parte de las tareas del hogar, llevadas a cabo especialmente por las mujeres aymaras, que además incluyen el cuidado de los hijos.

A diferencia del barrio 16 de Julio, netamente comercial y céntrico, en la periferia resaltan las siguientes prácticas cotidianas híbridas: la cría de ganado y/o la presencia de huertas dentro de la propia vivienda o en espacios públicos comunes. Esto último puede deberse en parte a la menor

\footnotetext{
${ }^{33}$ Se destaca el uso residencial del suelo urbano, pero la presencia de las denominadas viviendas productivas relativiza este término, ya que puede combinarse un uso residencial y laboral.
} 
consolidación urbana que existe en la periferia y, del mismo modo, se vincula con las estrategias de acceso al hábitat de los hogares de migrantes que predominan en este barrio.

Estas actividades rurales pueden estudiarse como formas de socialización del consumo (no mercantilizadas y precapitalistas $)^{34}$ que son un elemento importante de las estrategias de reproducción de la familia que se complementan con los escasos recursos del hogar dada su inserción en empleos informales e inestables (Jaramillo et al, 1993; Topalov, 1979). Por ejemplo, la familia de Doña Alejandra (28 años) posee aves de corral en su casa, las cuales son utilizadas para el consumo familiar. En sus palabras: “(...) huevea y eso nos ayuda, sale casi un boliviano cada huevo, es muy caro".

Asimismo, estas prácticas tienen una vinculación estrecha con la autoconstrucción ${ }^{35}$ de la vivienda que configura una estrategia de acceso al hábitat de la población migrante ${ }^{36}$. Es importante destacar que esta estrategia representa el 85\% de la producción habitacional total de la ciudad de El Alto (Durán Chuquinia et al, 2007), la cual demuestra la capacidad de los sectores populares de "construir ciudad". Al mismo tiempo, hace ostensible los límites en el acceso al suelo urbano formal, socialmente construido pero apropiado privadamente, por ende mercantilizado ${ }^{37}$.

Esta práctica de autoconstrucción de la vivienda produce un modelo de hábitat particular: viviendas con paredes de adobe y patio adelante donde se halla generalmente una huerta y corrales para sus animales de consumo familiar. De igual manera, el espacio público se transforma en una extensión de la vivienda donde pastorean a sus animales y siembran.

A continuación se presentan imágenes que muestran las prácticas cotidianas de las familias de El Porvenir I de llevar a cabo actividades rurales en el predio de su vivienda y en espacios públicos, que revela una apropiación urbana particular.

\footnotetext{
${ }^{34}$ Esta forma de socialización es de consumo ya que apunta a la manera en que una sociedad satisface sus necesidades. No es mercantil y es precapitalista ya que esa satisfacción de las necesidades implica una producción cuyo fin es el suministro de un valor de uso. Igualmente posee valor de cambio, aunque sea potencial, al estar inserto en una sociedad mercantilizada.

${ }^{35}$ En El Porvenir I preponderan los hogares que autoconstruyeron su vivienda (86,4\%), y en el barrio 16 de Julio imperan los que no la autoconstruyeron (64,3\%) (Diaz, 2015).

${ }^{36}$ A nivel urbano, sólo el 15\% de las viviendas alteñas fueron construidas con una participación directa y/o indirecta del Estado que, pese a su perspectiva cuantitativa, dotó de viviendas de mejor calidad con acceso a servicios básicos, logrando mejorar las condiciones de vida de los beneficiarios (Durán Chuquinia et al, 2007).

${ }^{37}$ Lejos de la idealización de autores como Turner, el planteo de este artículo retoma los análisis de Pradilla Cobos y Topalov que se basaron en las ideas principales de F. Engels (Cravino, 2012).
} 
Figura 1: Patio y sembradío de una casa de El Porvenir I. Marzo 2011

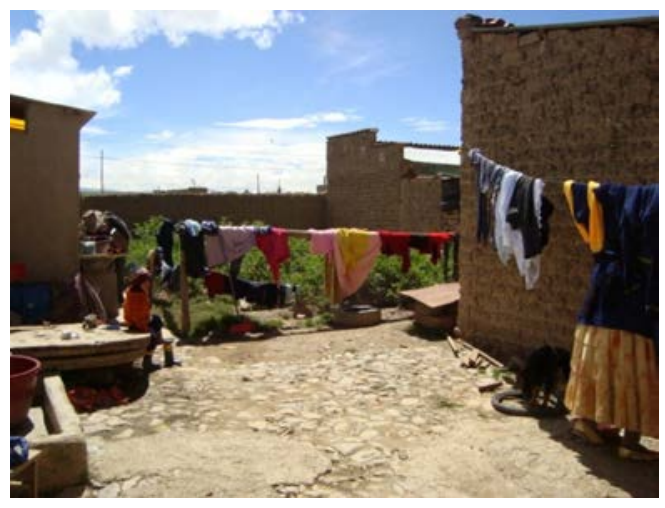

Fuente: Fotografía realizada por la autora.

Figura 2: Corral para las ovejas dentro de una casa del barrio El Porvenir I. Marzo 2013

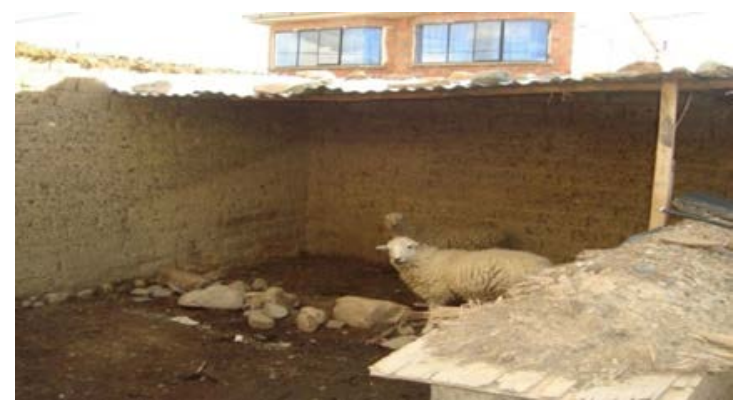

Fuente: Fotografía realizada por la autora.

Actualmente en los límites del barrio El Porvenir I se está formando un nuevo barrio, denominado 2 de Julio, donde se encuentran sembradíos a campo abierto. Además, en los lotes baldíos se pudo visualizar a los vecinos de la zona y de los barrios aledaños pastorear a sus animales.

Figura 3: Sembradíos en los límites del barrio El Porvenir I. Marzo 2013

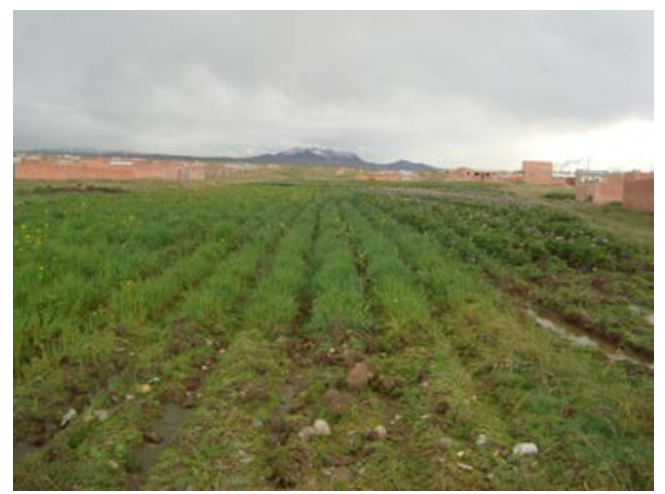

Fuente: Fotografía realizada por la autora. 
Figura 4: Ganado porcino en un terreno baldío del barrio El Porvenir I. Marzo 2013

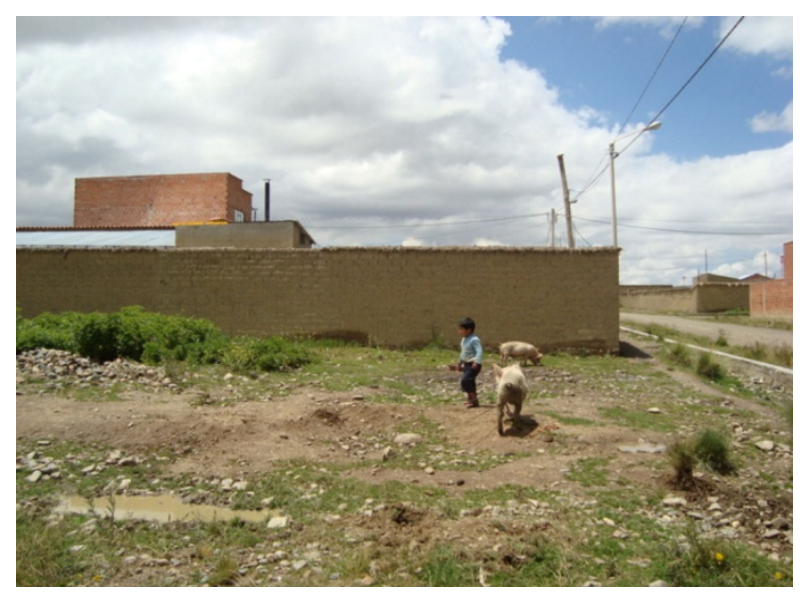

Fuente: Fotografía realizada por la autora.

Este escenario de prácticas cotidianas híbridas que da lugar a una mezcla de usos del suelo urbano-rural, es una característica propia de la periferia de la ciudad de El Alto, de baja consolidación urbana. Entonces, se encuentra una imbricación entre las dos áreas que, por esto, deben ser estudiadas en su unidad dialéctica como ámbitos que permiten la reproducción material de la unidad familiar en un hábitat segregado. Por ende, esta situación refuta la teoría de la modernización que presuponía el pasaje de una etapa tradicional y rural hacia otra moderna y urbana; o en términos de la Escuela de Chicago de los años 20 (Coulon, 2012), el tránsito de la rivalidad y el conflicto a la adaptación y la asimilación de la población migrante.

En cambio, en las viviendas del barrio céntrico 16 de julio, no se identificó la cría de animales para el consumo familiar ni sembradío. Tampoco se hallaron animales domésticos para el consumo en las calles o veredas del barrio, creando un paisaje muy diferente debido al gran tránsito de vehículos y a la cantidad de comercios que posee este barrio. Sobre esta cuestión Nelson, migrante de una comunidad rural del departamento de La Paz, refiriéndose a su vivienda comentó "no tenemos animales, solo gatito nada más, no tenemos patio es estrecha la tierra de mi mamá, es pequeña".

Figura 5: El barrio 16 de Julio. Noviembre 2011 


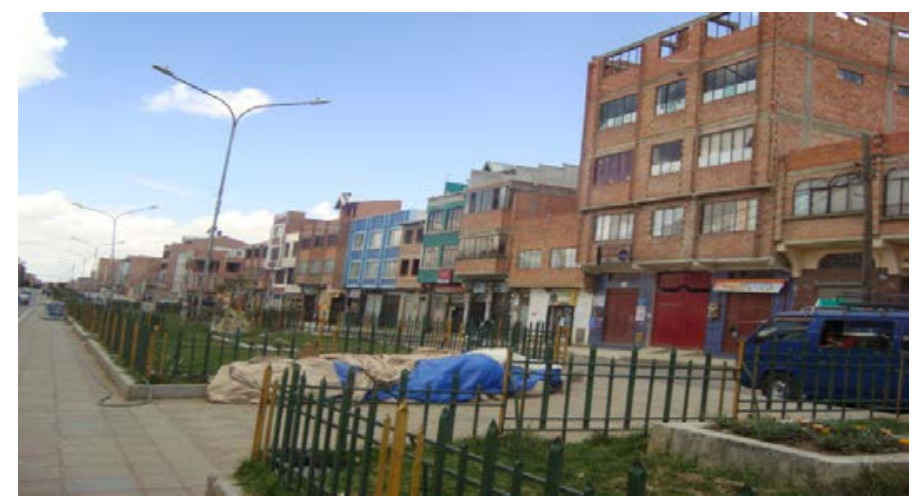

Fuente: Fotografía de la autora

No obstante, se concibe en este barrio una apropiación urbana distintiva: la feria 16 de Julio ${ }^{38}$ donde la calle se convierte en un mercado. En esta actividad se presenta una importante participación de mujeres que se debe a la construcción del mercado como un espacio tradicionalmente femenino en la vida de las ciudades andinas.

En El Porvenir I no se encuentran ferias ni mercados; realizan sus compras en la Feria 16 de Julio, que corresponde a los puntos focales primarios, y en forma frecuente a las que corresponden a los puntos focales secundarios que se localizan más cerca de su lugares de residencia. Al mismo tiempo, las mujeres venden sus productos deambulando en las distintas ferias de El Alto; mientras en 16 de Julio se entrevistaron comerciantes que poseen un puesto fijo en las mismas ${ }^{39}$.

La presencia de estas ferias es un símbolo de consolidación y de jerarquía de los barrios alteños (Cárdenas et al., 2010). Esta ausencia en la periferia en un ejemplo adicional de su baja consolidación urbana. Asimismo, esta interacción de los hogares de migrantes de El Porvenir I con las ferias de El Alto -y con la ciudad de La Paz por cuestiones laborales y/o visita a familiares, paseo, entre otras cuestiones- es una muestra de que la segregación que padecen no es asimilable a un gueto.

\section{Movimiento pendular campo-ciudad: Intensidad desigual}

38 Las ferias son sectores informales (productores mercantiles simples en circuitos no capitalistas) que proveen bienes y servicios en forma mercantilizada y a precios inferiores que en una empresa capitalista formal. Es así que constituyen el sustento de la reproducción de la unidad familiar y, simultáneamente, son funcionales a la acumulación del capital periférico que se asienta en un régimen de salarios bajos (Jaramillo et al., 1993).

${ }^{39}$ Los residentes de El Porvenir I no poseen un puesto fijo en las ferias. Esto denota un empobrecimiento de estos sectores que no poseen los recursos suficientes para pagar su puesto. Por ese motivo, deambulan. 
En este contexto, cabe preguntarse por la relación de los hogares de migrantes en ambos barrios de la ciudad con sus comunidades rurales de origen. También, cómo ésta se articula con la posición del jefe de hogar en el mercado de trabajo y con la apropiación que hacen de sus lugares de residencia respecto a los usos del suelo urbano. Esto último tiene la intención de revelar una asociación entre dichas variables que no pretende agotar la explicación de este fenómeno.

Por un lado, la situación laboral de inestabilidad es uno de los factores más importantes que explican los diferentes grados (según barrio) de interrelación de los migrantes con sus comunidades rurales. En El Porvenir I, el 87,2\% del total de los hogares con adultos nacidos en el campo regresan durante el año a sus comunidades de origen y, en el barrio 16 de Julio, el $50 \%$ de los mismos. En este último caso, ocurre una fragmentación donde sólo la mitad regresa a su comunidad, mientras en la periferia es lo que prepondera (87\%). Entonces, en El Porvenir I se expresa con mayor intensidad la relación continua entre el campo y la ciudad, constituyendo el primero un mecanismo adicional para garantizar la reproducción material de la familia.

\section{Cuadro 7: Relación con la comunidad de origen. Total de hogares con adultos nacidos en el campo de los barrios El Porvenir I y 16 de Julio. Año 2012. En porcentajes.}

\begin{tabular}{|c|c|c|c|}
\hline & \multicolumn{2}{|c|}{$\begin{array}{c}\text { ¿Durante el año hay alguna época en que alguno/s de los miembros de la familia } \\
\text { vuelva }(\mathrm{n}) \text { a la comunidad? }\end{array}$} \\
\hline $\begin{array}{c}\text { Nombre del } \\
\text { Barrio }\end{array}$ & Sí & No & Total \\
\hline El Porvenir I & 87,2 & 12,8 & $100(47)$ \\
\hline 16 de julio & 50 & 50 & $100(20)$ \\
\hline
\end{tabular}

Fuente: Elaboración propia según encuesta realizada en el 2012

Los migrantes de los dos barrios que regresan a la comunidad rural, lo hacen para los momentos del año de cosecha y siembra (75,6\% en El Porvenir I y $70 \%$ en 16 de Julio).

Cuadro 8: Motivo por el cual vuelve( $n$ ) a la comunidad de origen. Total de hogares con adultos nacidos en el campo de los barrios El Porvenir I y 16 de Julio. Año 2012. En porcentajes. 


\begin{tabular}{|c|c|c|c|c|c|}
\hline $\begin{array}{c}\text { Nombre del } \\
\text { Barrio }\end{array}$ & $\begin{array}{c}\text { ¿Por qué motivo vuelve }(\mathrm{n}) \text { a la comunidad de origen? } \\
\text { Cosecha/ siembra o } \\
\text { cosecha/siembra y fiestas }\end{array}$ & $\begin{array}{c}\text { Sólo } \\
\text { fiestas }\end{array}$ & $\begin{array}{c}\text { Visita a familiares o } \\
\text { vacaciones }\end{array}$ & $\begin{array}{c}\text { Otro } \\
\mathrm{s}^{40}\end{array}$ & \begin{tabular}{c} 
Total \\
\hline El Porvenir I
\end{tabular} \\
\hline 16 de julio & 75,6 & 4,9 & 17,1 & 2,4 & 100 \\
$(41)$
\end{tabular}

Fuente: Elaboración propia según encuesta realizada en el año 2012

Para profundizar esta información e intentar dar una explicación son importantes las entrevistas realizadas a los miembros de los hogares de ambos barrios. En primer lugar, los que regresan al campo son aquellos que poseen tierra $y$, por ello, tienen obligaciones con su comunidad, y/o familiares que radican allí. Otros factores para volver o no a la comunidad son la distancia (o el tiempo de viaje), los conflictos familiares en torno a la subdivisión de las parcelas, y la aparición de los surcofundios (parcelas más pequeñas aún que los minifundios). Esto hace referencia al problema de la estabilidad familiar debido a la orfandad o a nuevos matrimonios dentro de la familia, lo que implica la pérdida de derechos sobre los terrenos a favor de algún otro pariente o del nuevo vínculo matrimonial.

Tabla 1: Similitudes y diferencias en los motivos para regresar a la comunidad y en los usos de los productos rurales según barrio

\begin{tabular}{|c|c|}
\hline Similitudes & Diferencias \\
\hline $\begin{array}{c}\text { Poseen tierra y/ o } \\
\text { familiares }\end{array}$ & $\begin{array}{c}16 \text { de Julio: cuestión coyuntural por subida de precios post-gasolinazo y } \\
\text { visitas esporádicas }\end{array}$ \\
\cline { 2 - 2 } & $\begin{array}{c}\text { Productos para consumo familiar (El Porvenir I) vs. Para venta en negocio } \\
\text { familiar (16 de Julio) }\end{array}$ \\
\hline Mayor lazo con la comunidad en El Porvenir I que en 16 de Julio \\
\hline Fuente: Elaboración propia
\end{tabular}

Entre los principales motivos nombrados para regresar a la comunidad, la mayoría de los entrevistados en El Porvenir I señalaron que los productos del campo los utilizan para el consumo familiar. En sus palabras:

Yo vuelvo a Los Andes, a veces sola, con mi esposo, a veces con mis hijos, a veces todos, a escarbar papa, me traigo papa, habas para comer para mis hijos. Yo ahorita tengo cinco hijos, cada dos meses, un mes, a veces de dos semanas yo voy a traer mi papita. Al pueblo de mi esposo no vamos, lejos es, al año una vez para semana santa. (...) Sí, tengo tierra en Los Andes, recién estamos terminando de repartir la tierra, dos están allá en el campo, y dos estamos acá en El Alto (...). (Nancy, 39 años, vende en las ferias de El Alto los

\footnotetext{
${ }^{40}$ Dentro de "Otros" se incluyen a los que respondieron para hacer comercio o cuidar su propiedad.
} 
productos que teje, maneja un pequeño almacén del barrio, y su esposo es chofer de minibús).

Entre los factores descriptos para no regresar a la comunidad de origen, se puede nombrar en este barrio periférico la historia de Angelina (65 años).

La familia se aprovecha también, está mi tío, mi mamá se había muerto, en el pueblo de Jesús de Machaca había tenido un terreno pero mi tío se lo ha agarrado, los papeles ha sacado, lo ha partido entre sus hijos y a mí no me ha dado nada. No me han dado nada, ni siquiera un pedacito. No me traigo nada de allá, solo voy a visitar a veces me da papitas a veces me invita. He sufrido tanto que ya no quiero ir más pues. Es cerca pues pero ya no quiero ir más. (Angelina, 65 años, vende en las ferias de El Alto las chombas que teje, su esposo es albañil).

La relación con el campo permite a las familias de El Porvenir I reproducirse materialmente en la ciudad. Ante la escasez de recursos económicos, mediante relaciones no mercantiles, se proveen de valores de uso necesarios, que en general son para el consumo familiar. De este modo, los productos que reciben de la comunidad rural igualmente constituyen formas de socialización del consumo pre-capitalista (no mercantilizada) necesarios para la reproducción de los miembros del hogar.

Es así que una parte importante de la reproducción social se lleva a cabo por "fuera" del modo de producción capitalista dominante. Pese a esto, la problemática de la segregación residencial de los sectores populares en el barrio periférico es funcional a la acumulación capitalista periférica que se basa en un régimen de salarios bajos que gira alrededor de un proceso de reproducción de la fuerza de trabajo que no descansa solamente en la relación salarial propiamente dicha ${ }^{41}$.

\footnotetext{
${ }^{41}$ El modo de producción capitalista absorbe aquellos elementos que le son ajenos, y los convierte en funcionales a la acumulación del capital ya que estas formas pre-capitalistas permiten el descenso del valor de la fuerza de trabajo del conjunto de los trabajadores (Topalov, 1979). Desde la visión de Marx en El Capital, la población migrante de origen rural residente en la periferia puede estudiase como parte de la sobrepoblación relativa (que puede adoptar continuamente tres formas: fluctuante, latente y estancada). Esta es definida como "material humano explotable y siempre disponible" para las variables necesidades de valorización de capital que ejerce una presión sobre el sector ocupado de la clase obrera, obligándolos a aceptar salarios muy bajos y a trabajar excesivamente bajo el mando del capital. A su vez, esta población inserta en actividades informales e inestables puede estudiarse como parte de la superpoblación estancada, que constituye una parte del ejército obrero activo pero su ocupación es irregular. De este modo sus condiciones de vida se caracterizan por el pauperismo porque se hallan por debajo del nivel medio normal de la clase obrera.
} 
En contraste, en el barrio 16 de Julio, los migrantes subrayaron una cuestión coyuntural en relación a su visita a la comunidad, ligada a la subida de precios de los alimentos post-gasolinazo ${ }^{42} \mathrm{O}$ sólo como visita esporádica por la falta de tiempo.

A la comunidad, sí vuelvo al año una vez o dos veces nada más, voy a sembrar y luego a recoger papa, haba, eso nomás. Y para mi mantención me traigo. Ahora las cosas han subido entonces ya me obliga ir a cosechar, más antes no iba y mis ventas de sal también han rebajado y de ese motivo voy a cosechar más, antes no iba. (Nadia, 46 años, comerciante de sal).

Mis papás siguen en la comunidad, no hay tiempo para ir a visitar, con el negocio no hay tiempo. Ellos vienen a visitarnos al año una vez. Cuando vamos un par de horas, no cosechamos nada. (Wendy, 26 años, junto con su esposo son dueños de una carnicería).

En este barrio céntrico, especialmente las familias que regresan a las comunidades por los motivos destacados, utilizan los productos del campo para el consumo familiar y, especialmente resaltan aquellos que los venden en su negocio familiar.

Vamos a las comunidades de mi mamá y de mi papá, traemos papitas, cosechamos, vamos dos veces al año (...) Traemos la papa para comer, para vender, para comercializarlo, tenemos una pensión (un restaurante), para cocinar, para vender. El restaurante era de mi mamá que, en paz descanse, ha fallecido. Lo vamos a manejar mis hermanos y yo. (Nelson, comerciante, 32 años, soltero).

Por otra parte, se presentaron migrantes que no tienen parcela propia en el campo, por consiguiente, regresan a la comunidad de origen especialmente para mantener los lazos familiares $y$, en menor medida, por necesidad de proveerse de alimento para sobrevivir en la ciudad.

Sí, el 6 de agosto cada año vamos la familia a la comunidad, por lo menos a compartir un platito, se recuerda el día de la patria, allá desfilan alumnos los de la comunidad, las autoridades. (...) Solamente a esas fiestas. Mi papá tenía también unas partecitas que le regaló mi abuelo y se lo ha vendido. A mi parecer bien, porque he visto ahora se cumplen funciones de autoridad si no cumples esas funciones también está mal visto en la comunidad, eso yo veo (...).

En 16 de Julio, entre los migrantes que regresan a sus comunidades, se encuentra una heterogeneidad de situaciones. No obstante, predominan aquellos casos en lo que los viajes al campo sirven para traer los productos agrícolas que les permiten potenciar su situación económica o complementar la economía familiar. En contraste, en El Porvenir I imperan los que alegan la necesidad de esos productos para subsistir en la ciudad, o como estrategia de reproducción

\footnotetext{
${ }^{42}$ En el año 2010, el Gobierno de Evo Morales determinó el incremento de los combustibles en casi un 100\%. Esta medida provocó un alza de los precios de los alimentos de primera necesidad en la misma proporción. Si bien por presión popular se derogó la medida, los precios de la canasta familiar se mantuvieron inalterables (Quispe Alvarado, et al, 2011).
} 
material de las familias, compuestas en mayor medida por jefes de hogar que se insertan en empleos informales no consolidados (inestables).

Por consiguiente, se demuestra las "contra-tendencias" al proceso de descampenización, que profundizó el modelo neoliberal, ya que los movimientos pendulares campo-ciudad generan una "recampenización" continúa que posee una intensidad desigual según localización centroperiferia. Esto se debe en parte a la dinámica urbana de la ciudad de El Alto y a las trayectorias migratorias. Como se ha remarcado, el crecimiento poblacional de los barrios de la periferia de la ciudad es reciente, ligado a la urbanización neoliberal. Los mismos concentran a los migrantes de primera generación, quienes luego de haber atravesado varias etapas migratorias lograron asentarse como propietarios de su vivienda en estas áreas de baja consolidación.

\section{CONCLUSIONES}

La conformación de los barrios 16 de Julio y El Porvenir I son una muestra de la dinámica del crecimiento urbano de El Alto que se asocia con el proceso de urbanización y metropolización de la ciudad de La Paz. Pese a la distancia temporal, fue el loteamiento informal la causa principal que dio origen a ambos barrios.

Lo relatado pone en evidencia uno de los rasgos de las urbes latinoamericanas: el crecimiento veloz de las ciudades por fuera de todo tipo de planificación estatal, y al mismo tiempo la estrategia de los loteadores informales de producir en las periferias "suelo urbano sin urbanización" (Pirez, 2014) con el fin de maximizar su ganancia. Además, se hallaron rasgos específicos en el proceso de urbanización de las urbes andinas, como por ejemplo: la estructura colonial particular de las haciendas, el peso de la población indígena y de las áreas rurales que continúa en la actualidad.

Simultáneamente, se intentó demostrar que, lejos de la visión homogeneizante, la ciudad de El Alto presenta una diferenciación socio-espacial, y un desarrollo urbano desigual y combinado ligado a la baja provisión de valores de uso complejo. Esta situación caracteriza a los países periféricos en términos generales y especialmente a los países más pobres de la región. Como se detalló, los sectores populares no son uniformes sino que pueden encontrarse capas más empobrecidas unas respecto a las otras que se distribuyen de manera desigual en el territorio urbano según la localización centro-periferia.

Es importante resaltar que la segregación residencial que padecen los migrantes aymaras en la periferia indica un tipo de hábitat donde coexiste la formalidad dominial en un contexto 
urbano homogéneamente precario dada las deficiencias respecto a la provisión de equipamientos colectivos y de infraestructura urbana. En el barrio 16 de Julio el tipo de hábitat se define por la heterogeneidad respecto a la situación de precariedad (en un contexto de mayor consolidación urbana) y el predominio también de la formalidad urbana.

Esto demuestra que la mera política de regularización de la situación dominial no es suficiente para alcanzar la ansiada mejora del hábitat. Es pertinente el desarrollo no sólo de políticas urbanas integrales por parte del Estado que prioricen el déficit cualitativo de la vivienda (y del hábitat) sino también de políticas que se enfoquen en una reestructuración del mercado laboral que combata las altas tasas de informalidad laboral reinante en un país con limitados recursos públicos. Esta cuestión abre la posibilidad de repensar no sólo la ciudad informal en América Latina sino también la relación entre la formalidad y la precariedad urbana.

Por su parte, los migrantes residentes en el barrio de la periferia despliegan múltiples estrategias de reproducción material de la familia en su vida cotidiana, en una ciudad que los relega a empleos no sólo informales sino inestables. Las prácticas cotidianas híbridas que desarrollan en el barrio implican una apropiación del espacio urbano público y privado que produce un tipo de hábitat donde ocurre una mixtura de usos del suelo urbano y rural; posibilitado por la menor consolidación urbana que posee la periferia de la ciudad.

Estas prácticas no forjan islas de ruralidad sino territorios rururbanos insertos en una ciudad que presenta un desarrollo urbano desigual y combinado. Asimismo, estas actividades son realizadas por las mujeres aymaras del hogar. Esto último genera una reclusión parcial de dichas mujeres, temática que excede esta presentación.

Conjuntamente, estas prácticas cotidianas híbridas se articulan con los productos que reciben del área rural (especialmente para el consumo familiar), y constituyen formas de socialización del consumo de manera no mercantilizada y pre-capitalista. Estas se complementan con el régimen de salarios bajos que predomina en la acumulación capitalista periférica. En este contexto general, los lazos con las comunidades de origen son, en mayor medida, necesarios para alcanzar la reproducción mínima de los miembros del hogar en el ámbito urbano periférico.

En síntesis, lo urbano y lo rural no son dos áreas separadas sino que se halla una imbricación entre ambas. Además, estas formas de socialización del consumo no mercantiles se combinan con las formas mercantiles, representadas por las ferias, que implican una apropiación urbana particular donde la calle se convierte en un mercado. 
En el barrio 16 de Julio, los migrantes (que conforman una minoría ya que actualmente se concentran los hogares de no migrantes) se integran en un espacio urbano de mayor consolidación y se insertan en actividades informales consolidadas que les provee de mayores recursos económicos. Por consiguiente, la interacción con el campo es menor y para los que regresan principalmente les permite potenciar o complementar la economía del hogar en un barrio donde imperan las formas mercantiles de reproducción de la familia. Aunque es probable que en los inicios de su consolidación (entre los años 1950 y 1980) hayan prevalecido las diversas formas "pre capitalistas" de socialización del consumo.

Por ende, las desiguales situaciones de estos barrios- respecto a la cobertura de los equipamientos comunitarios, de infraestructura y del servicio de transporte; en relación a la dinámica urbana, laboral, migratoria; y a las prácticas cotidianas de la población-responden a los distintos momentos de crecimiento urbano alteño que se vinculan con la antigüedad de los mismos. Por otra parte, se presentó una intensidad desigual en la relación de los migrantes con sus lugares de origen, dependiendo de su localización y especialmente del tipo de inserción laboral. Este hallazgo permite debatir con la visión que postula la tendencia progresiva a la descampenización. Es decir, es el puntapié para reflexionar sobre los procesos complejos y contradictorios de descampenización-recampenización tan propio de la región andina.

Finalmente, el Derecho a la Ciudad, desde una postura inmediata incluye una diversidad de derechos, entre ellos: el derecho a una vivienda digna y a un trabajo adecuado. Por lo tanto, el análisis de la dinámica urbana y laboral de la población migrante según área de residencia plantea la imposibilidad de un goce efectivo de este derecho si no se produce una transformación cualitativa en el mercado laboral y en las políticas públicas referidas al hábitat. Empero, si se reflexiona sobre la posibilidad de un cambio social, como señala Harvey (2012), este derecho involucra un mayor control democrático sobre la producción y el uso del excedente en tanto ejercicio colectivo y libertario de remodelación de los procesos de urbanización y de la relación con la naturaleza.

\section{BIBLIOGRAFÍA}

ABRAMO, Pedro. Producción de las ciudades latinoamericanas: informalidad mercado del suelo. En María Cristina Cravino (comp.), Repensando la ciudad informal en América Latina. Buenos Aires, Universidad Nacional de General Sarmiento, pp. 199-232, 2012. 
ADASZKO, Dan. Segregación residencial socioeconómica y desigualdad en la distribución espacial y en el acceso a bienes urbanos fundamentales en la Argentina de comienzos del nuevo milenio. Tesis de doctorado. Buenos Aires: Facultad de Ciencias Sociales de la Universidad de Buenos Aires, 2013.

AMENDOLA, Giandomenico. La ciudad posmoderna. España: Celeste ediciones, 2000

ADAD TORRICO, Aida. La Paz: Proceso Urbano, Centro histórico y Espacio Social. La Paz: Universidad Privada Franz Tamayo, 2004.

ARBONA, Juan Manuel. Eso es ser pobre e indio en este país. Repercusiones urbanas e implicaciones sociales de la discriminación y la exclusión: lecciones de El Alto, Bolivia. En María del Carmen Zabala Arguelles (Comp.), Pobreza, exclusión social y discriminación étnico-racial en América Latina y el Caribe. Bogotá: CLACSO, pp. 349-370, 2008.

ARBONA, Juan Manuel y COLLEGE, Bryn. Dinámicas barriales y espaciales en la construcción de un barrio alteño. Colombia Internacional, Colombia, N 73, p. 91-120, enero -junio 2011.

BORJA, Jodi. Espacio público y derecho a la ciudad. Revista viento sur, España, №116, p.39-49, mayo 2011.Marx el capital, 2011.

CAMARERO, Hernán. De la estructura a la experiencia. Las ciencias sociales y sus visiones sobre la clase obrera argentina (1955-1969). En Hernán Camarero, Pablo Pozzi y Alejandro Schneider (Cood.), De la revolución libertadora al menemismo. Historia social y política argentina. Buenos Aires: Colección Bitácora Argentina, 2000.

CASTELLS, Manuel. La Cuestión Urbana. Buenos Aires: Siglo Veintiuno Editores, 1974.

CUADROS, Alvaro. La Paz. La Paz: FAU-CDALP-COBBE, 2003.

CLICHEVSKY, Nora. Informalidad y Segregación urbana en América Latina. Una aproximación. Chile, CEPAL, 2000.

Pobreza y acceso al suelo urbano. Algunas interrogantes sobre las políticas de regularización en América Latina. Chile, CEPAL, 2003.

COULOMB, René. Las políticas habitacionales de los estados latinoamericanos. Seminario Taller Internacional Teorías sobre la ciudad. Buenos Aires: Universidad Nacional de General Sarmiento, 2012.

COULON, Alain. L'École de Chicago. Paris: Presses Universitaires de France, 2012.

CRAVINO, María Cristina. Debates sobre los asentamientos informales en América latina. En María Cristina Cravino (comp.), Repensando la ciudad informal en América Latina. Buenos Aires, Universidad Nacional de General Sarmiento, pp. 13-104, 2012.

DEMORAES, Florent. Etude de l'evolution de l'agglomeration de La Paz-El Alto depuis les vingt dernieres annees compte tenu des contraintes environnement du site. Tesis de grado de magister. Chambery (Francia): Universidad de Savoie, Departamento de Geografía, 1998. 
DE SOTO, HERNANDO (2003). El misterio del Capital. Lima: Ediciones El Comercio.

DIAZ, Mariela Paula (2013). El Alto- La Paz (Bolivia): Las transformaciones socio- territoriales del neoliberalismo y la derrota del movimiento obrero. Les Cahiers ALHIM, Francia, n 26, pp.1-26, 2013.

DIAZ, Mariela Paula. Hábitat popular y mercado laboral: El desarrollo urbano desigual de la ciudad de El Alto (Bolivia). Revista INVI, 30 (85), Santiago de Chile, pp. 111-145, 2015.

DI VIRGILIO, María Mercedes. Trayectorias residenciales y estrategias habitacionales de familias de sectores populares y medios en Buenos Aires. Tesis de doctorado. Buenos Aires: Facultad de Ciencias Sociales (UBA), 2007.

DUHAU, Emilio. División social del espacio metropolitano y movilidad residencial. Revista Papeles de Población, 36, México, p.161-210, 2003.

DUREAU, Françoise. Sistemas residenciales. Conceptos y aplicaciones. Revista Territorios, 11, Colombia, p. 41-70, 2004.

DO ALTO, Hervé. Cuando el nacionalismo se pone el poncho. Una mirada retrospectiva a la etnicidad y la clase en el movimiento popular boliviano (1957-2007). En Maristella Svampa, y Pablo Stefanoni, Bolivia. Memoria, insurgencia y movimientos sociales. Buenos Aires: Editorial El Colectivo, pp. 21-53, 2007

DUNKERLEY, James. Rebelión en las venas. La Paz: Plural editores, 2003.

DURAN CHUQUINIA, Jaime, ARIAS DÍAZ, Verónica y RODRÍGUEZ CÁCERES, Gustavo. Casa aunque en la Punta del Cerro. Vivienda y Desarrollo de la Ciudad de El Alto. La Paz: Fundación PIEB, La Paz, 2007.

FERNANDEZ WAGNER, Raúl, GROISMAN, Fernando, et al. Aportes para el desarrollo humano en la Argentina. Segregación residencial en Argentina. Buenos Aires: PNUD, 2009.

GROISMAN, Fernando y SUÁREZ, Ana, Lourdes. Segregación residencial e inserción laboral en el conurbano bonaerense. Población de Buenos Aires. 7 (11), Buenos Aires, pp. 7-28, 2010.

GROISMAN, Fernando y SUÁREZ, Ana Lourdes. Segregación residencial en la Ciudad de Buenos Aires. Revista Población de Buenos Aires, 4(3), pp. 27-37, 2006

GARFIAS, Sandra y MAZUREK, Hubert. El Alto, desde una perspectiva poblacional. La Paz: CODEPOIRD, 2005.

GONZÁLEZ CASANOVA, Pablo. Sociedad plural, colonialismo interno y desarrollo. En Fernando, Cardoso, Aníbal, Pinto y Osvaldo, Sunkel (Comp.), América Latina, ensayos de interpretación sociológico-política. Santiago de Chile: Editorial Universitaria, Colección Tiempo latinoamericano, p. 164-183, 1970 
GOZALVEZ, Bertha. Definición de áreas homogéneas en la ciudad de La Paz. En Jorge Cordova y Jean Claud Roux. Primera Reunión Nacional de Geografía Boliviana de 1995. La Paz: UMSA-ORSTOM, pp. 171-188, 1996.

GUAYGUA, Germán. Identidad colectiva y movilidad social en la ciudad de El Alto. En Germán Guaygua, Claudia Peña y Adrián Waldmann, Nuevas identidades urbanas. Tres miradas desde la cultura y la desigualdad. La Paz: PNUD, pp. 237-318, 2011.

GUAYGUA, Germán y ESCOBAR DE PABÓN, Silvia. Estrategias familiares de trabajo e inserción laboral de los hogares. Buenos Aires: Colección CLACSO-CROP, 2008.

HARVEY, David. El nuevo imperialismo: Sobre reajustes espacios-temporales y acumulación mediante desposesión. Revista Viento Sur, 1 (447), España, pp. 1-26, 2004.

(2007). Urbanismo y desigualdad social. España: Siglo XXI Editores.

El enigma del Capital y las crisis del capitalismo. Madrid: ediciones Akal, 2010. 2012.

Rebel Cities. From the right to the city to the urban revolution. Londres-Nueva York: Verso,

HERZER, Hilda Org. Con el corazón mirando al sur. Transformaciones en el sur de la ciudad de Buenos Aires. Buenos Aires: Espacio Editorial, 2008.

JARAMILLO, Samuel y CUERVO, Luis Mauricio. La urbanización Latinoamericana. Nuevas Perspectivas. Colombia: Escala, 1993.

Reflexiones sobre la informalidad fundiaria como peculiaridad de los mercados del suelo en las ciudades de América Latina. En María Crisitna Cravino, Repensando la ciudad informal en América Latina. Buenos Aires: Universidad Nacional de General Sarmiento, pp. 149-197, 2012.

KLEIN, Herbert. Historia de Bolivia. La Paz: Librería Editorial Juventud, 2000.

LANDER, Edgardo. El Estado en los actuales procesos de cambio en América Latina: Proyectos / procesos de cambio complementarios/divergentes, en sociedades heterogéneas. Ponencia presentada en el Seminario internacional Societal Transformation and Political Steering in Latin America and Europe. Bélgica: Fundación Rosa Luxemburg o, junio de 2011.

LEFEBVRE, Henri. El Derecho a la ciudad. Barcelona: Ediciones Península, 1969.

De lo Rural a lo Urbano. Barcelona: Ediciones Península, 1978.

LOMBARDO, Juan Donato. La construcción del espacio urbano. Sus características en el Área Metropolitana de Buenos Aires. Buenos Aires: ediciones Ciccus/Universidad Nacional de General Sarmiento, 2012.

MAMANI RAMÍREZ, P. El rugir de las multitudes. La fuerza de los levantamientos indígenas en Bolivia/Qullasuyu. La Paz: Ediciones Yachaywasi, 2004.

MARX, Carl. La ley general de la acumulación capitalista. En El capital. Buenos Aires: Siglo XXI, Tomo I, Vol. 3, 2004. 
MAZUREK, Hubert. Lo urbano: la cristalización de lo social y de lo espacial. En Fernanda Wanderley (Coord.), Estudios Urbanos. En la encrucijada de la interdisciplinariedad. La Paz: CIDES-UMSA, pp. 2756, 2009.

MASSEY, Douglas y DENTON, Nancy. The dimensions of residential segregation. Social Forces, 67 (2), Reino Unido, pp. 281-315.

NEFFA, Julio César. Naturaleza y significación del trabajo/empleo precario. En Mariana Busso y Pablo Pérez (Coords), La corrosión del trabajo. Estudios sobre la informalidad y la -precariedad laboral. Buenos Aires: CEIL PIETTE- CONICET, pp.17-50, 2010

PEREIRA MORATÓ, René. Las ciudades bolivianas, ¿cómo entenderlas? Migración y urbanización. En Fernanda Wanderley (Coord.), Estudios Urbanos. En la encrucijada de la interdisciplinariedad. La Paz: CIDES-UMSA, pp. 95-117, 2009.

PIREZ, Pedro. La urbanización "inversa" en América Latina y la desmercantilización social. Ponencia presentada en las II Jornadas de Estudios de América Latina y el Caribe: desafíos y debates actuales, 24 al 26 de septiembre. Buenos Aires, 2014.

PORTES, Alejandro y HALER, William. La economía informal. Chile: CEPAL, 2004.

PRADILLA COBOS, Emilio. Los límites del concepto proceso de urbanización. Diseño UAM, $\mathrm{N}^{\circ} 4$, Universidad Autónoma Metropolitana, México, pp. 24-35, 1986.

Teorías y Políticas Urbanas ¿Libre mercado mundial, o construcción regional. Estudos Urbanos e Regionais, 12 (2), Brasil, p.9-21, 2010.

QUIJANO, Aníbal. Dependencia, cambio social y urbanización en América Latina. En Marta SCHTEINGART (comp.), Urbanización y dependencia en América Latina. Buenos Aires: Ediciones SIAP, pp. 19-69, 1973.

QUIJANO, Aníbal. Colonialidad del poder, eurocentrismo y América Latina. En Edgardo Lander. La colonialidad del saber: eurocentrismo y ciencias sociales. Perspectivas latinoamericanas. Buenos Aires: UNESCO-CLACSO, p. 201-246, 2000.

QUISPE ALVARADO, David, TONCONI MAMANI, Florencia y CANAVIRI MAMANI, Celia. Warmis alteñas en el puesto de la vida. Testimonio económico y político de las mujeres del comercio minorista en la ciudad de El Alto. El Alto: Centro de Promoción de la Mujer Gregoria Apaza, 2011.

RAMÍREZ CORZO, Daniel y RIOFRIO, Gustavo. Formalización de la propiedad y mejoramiento de barrios: bien legal, bien marginal. Lima: desco. Programa Urbano, 2006.

RIVERA CUSICANQUI, Silvia. Ch'ixinakax utxiwa: una reflexión sobre prácticas y discursos descolonizadores. Buenos Aires: Tinta Limón, 2010.

ROJAS, BRUNO y ROSSELL, Pablo. Destino incierto: esperanzas y realidades laborales de la juventud alteña. La Paz: CEDLA, 2006.

RODRÍGUEZ, Gonzalo. Segregación residencial socioeconómica en la ciudad autónoma de Buenos 
Aires. Dimensiones y cambios entre 1991 y 2001. Revista Población de Buenos Aires, 5(8), Buenos Aires, p. 7-30, 2008.

ROJAS C., B. y GUAYGUA, G. (2001). El empleo en tiempo de crisis. Cambios en los mercados de trabajo y en la calidad del empleo en la ciudad de El Alto. La Paz: CEDLA.

SABATINI, Francisco, Cáceres, Gonzalo y Cerda Jorge. Segregación residencial en las principales ciudades chilenas: Tendencias de las tres últimas décadas y posibles cursos de acción. Revista Eure, 27 (82), Santiago de Chile, p. 1-34, 2001.

SADER, Emir. Posneoliberalismo en América Latina. Buenos Aires: CLACSO, 2008.

SANDOVAL, Godofedro y SOSTRES, Fernanda. La ciudad prometida. Pobladores y organizaciones sociales en El Alto. La Paz: ILDIS-SYSTEMA, 1989.

SMITH, Neil. La geografía del desarrollo desigual. En Dunn, B y Radice, H. 100 years of permanent revolution: Results and prospects. Londres: Pluto press, 2006.

STAVENHAGEN, Rodolfo. Siete tesis equivocadas sobre América Latina. En América Latina, ensayos de interpretación sociológico-política. Santiago de Chile: Editorial Universitaria, pp. 82-93, 1965

STEBE, Jean Marc y Hervé, Marchal. La Sociologie Urbaine. Paris: Presses Universitaires de France, 2011.

SVAMPA, Maristella. Renunciar al Bien Común. Extractivismo y (pos)desarrollo en América Latina. Buenos Aires: editorial Mardulce, 2012.

TOPALOV, Christian. La urbanización capitalista. México: Edicol, 1979.

TORNAROLLI, Leopoldo y GASPARINI, Leonardo. Labor informality in Latin America and the Caribbean: Patters and trends from household survey Microdat. Revista Desarrollo y Sociedad, 63, Colombia, pp. 13-80, 2009.

TORNAROLLI, Leoploldo, BATTISTÓN, Diego, GASPARINI, Leonardo y GLUZMANN, Pablo. Exploring trends in labor informality in Latin America, 1990-2010. Documentos de Trabajo CEDLAS, 159, La Plata (Buenos Aires), pp. 1-55, 2012.

VESCHAMBRE, Vincent. La notion d'appropriation. Norois Revues, 195, Francia, pp. 115-116, 2005.

WANDERLEY, Fernanda. Crecimiento, empleo y bienestar social. ¿Por qué Bolivia es tan desigual? La Paz: Plural editores, 2009.

YUJNOVSKY, Oscar. Claves políticas del problema habitacional argentino 1955-81. Buenos Aires: Grupo Editor Latinoamericano, 1984. 


\section{Documentación oficial}

CÁMARA DEPARTAMENTAL DE INDUSTRIAS DE LA PAZ Y EL PROGRAMA DE COOPERACIÓN DANESA AL SECTOR MEDIO AMBIENTE (2003), Primer Censo de Establecimientos Económicos de la Industria Manufacturera en la ciudad de El Alto, Bolivia.

Trabalho enviado em 09 de setembro de 2016.

Aceito em 28 de outubro de 2016. 